\title{
Methane emissions from dairies in the Los Angeles Basin
}

\author{
Camille Viatte $^{1}$, Thomas Lauvaux ${ }^{2}$, Jacob K. Hedelius ${ }^{1}$, Harrison Parker ${ }^{3}$, Jia Chen $^{4, a}$, Taylor Jones ${ }^{4}$, \\ Jonathan E. Franklin ${ }^{4}$, Aijun J. Deng ${ }^{2}$, Brian Gaudet ${ }^{2}$, Kristal Verhulst $^{5}$, Riley Duren ${ }^{5}$, Debra Wunch ${ }^{1, b}$, \\ Coleen Roehl ${ }^{1}$, Manvendra K. Dubey ${ }^{3}$, Steve Wofsy ${ }^{4}$, and Paul O. Wennberg ${ }^{1}$ \\ ${ }^{1}$ Division of Geological and Planetary Sciences, California Institute of Technology, Pasadena, CA, USA \\ ${ }^{2}$ Department of Meteorology, Pennsylvania State University, University Park, PA, USA \\ ${ }^{3}$ Earth System Observations, Los Alamos National Laboratory, Los Alamos, NM, USA \\ ${ }^{4}$ School of Engineering and Applied Sciences, Harvard University, Cambridge, MA, USA \\ ${ }^{5}$ Jet Propulsion Laboratory, California Institute of Technology, Pasadena, California, USA \\ ${ }^{a}$ now at: Department of Electrical and Computer Engineering, Technical University of Munich, Munich, Germany \\ bnow at: Department of Physics, University of Toronto, Toronto, ON, Canada
}

Correspondence to: Camille Viatte (camille@gps.caltech.edu)

Received: 1 April 2016 - Discussion started: 27 April 2016

Revised: 11 April 2017 - Accepted: 25 April 2017 - Published: 21 June 2017

\begin{abstract}
We estimate the amount of methane $\left(\mathrm{CH}_{4}\right)$ emitted by the largest dairies in the southern California region by combining measurements from four mobile solar-viewing ground-based spectrometers (EM27/SUN), in situ isotopic ${ }^{13 / 12} \mathrm{CH}_{4}$ measurements from a CRDS analyzer (Picarro), and a high-resolution atmospheric transport simulation with a Weather Research and Forecasting model in large-eddy simulation mode (WRF-LES).

The remote sensing spectrometers measure the total column-averaged dry-air mole fractions of $\mathrm{CH}_{4}$ and $\mathrm{CO}_{2}$ $\left(X_{\mathrm{CH}_{4}}\right.$ and $\left.X_{\mathrm{CO}_{2}}\right)$ in the near infrared region, providing information on total emissions of the dairies at Chino. Differences measured between the four EM27/SUN ranged from 0.2 to $22 \mathrm{ppb}$ (part per billion) and from 0.7 to $3 \mathrm{ppm}$ (part per million) for $X_{\mathrm{CH}_{4}}$ and $X_{\mathrm{CO}_{2}}$, respectively. To assess the fluxes of the dairies, these differential measurements are used in conjunction with the local atmospheric dynamics from wind measurements at two local airports and from the WRF-LES simulations at $111 \mathrm{~m}$ resolution.

Our top-down $\mathrm{CH}_{4}$ emissions derived using the Fourier transform spectrometers (FTS) observations of 1.4 to $4.8 \mathrm{ppt} \mathrm{s}^{-1}$ are in the low end of previous top-down estimates, consistent with reductions of the dairy farms and urbanization in the domain. However, the wide range of inferred fluxes points to the challenges posed by the heterogeneity of the sources and meteorology. Inverse modeling from WRF-LES is utilized to resolve the spatial distribution
\end{abstract}

of $\mathrm{CH}_{4}$ emissions in the domain. Both the model and the measurements indicate heterogeneous emissions, with contributions from anthropogenic and biogenic sources at Chino. A Bayesian inversion and a Monte Carlo approach are used to provide the $\mathrm{CH}_{4}$ emissions of 2.2 to $3.5 \mathrm{ppt} \mathrm{s}^{-1}$ at Chino.

\section{Introduction}

Atmospheric methane $\left(\mathrm{CH}_{4}\right)$ concentration has increased by $150 \%$ since the pre-industrial era, contributing to a global average change in radiative forcing of $0.5 \mathrm{~W} \mathrm{~m}^{-2}$ (Forster et al., 2007; Myhre et al., 2013; IPCC, 2013). Methane is naturally emitted by wetlands, but anthropogenic emissions now contribute to more than half of its total budget (Ciais et al., 2013), ranking it the second most important anthropogenic greenhouses gas after carbon dioxide $\left(\mathrm{CO}_{2}\right)$.

The United Nations Framework Convention on Climate Change (UNFCCC, http://newsroom.unfccc.int/) aims to reduce $\mathrm{CH}_{4}$ emissions by reaching global agreements and collective action plans. In the United States (USA), the federal government aims to reduce $\mathrm{CH}_{4}$ emissions by at least $17 \%$ below 2005 levels by 2020 by targeting numerous key sources such as (in order of importance) agriculture, energy sectors (including oil, natural gas, and coal mines), and landfills (Climate Action Plan, March 2014). Methane emissions are quantified using bottom-up and top-down estimates. The 
bottom-up estimates are based on scaling individual emissions and process level information statistically (such as the number of cows, population density or emission factor) with inherent approximations. Top-down estimates, based on atmospheric $\mathrm{CH}_{4}$ measurements, often differ from these reported inventories both in the total emissions and the partitioning between the different sectors and sources (e.g., Hiller et al., 2014). In the USA, the disagreement in $\mathrm{CH}_{4}$ emissions estimated can reach a factor of 2 or more (Miller et al., 2013; Kort et al., 2014), and remains controversial regarding the magnitude of emissions from the agricultural sector (Histov et al., 2014). Thus, there is an acknowledged need for more accurate atmospheric measurements to verify the bottom-up estimates (Nisbet and Weiss, 2010). This is especially true in urban regions, such as the Los Angeles Basin, where many different $\mathrm{CH}_{4}$ sources (from farmlands, landfills, and energy sectors) are confined to a relatively small area of $\sim 87000 \mathrm{~km}^{2}$ (Wunch et al., 2009; Hsu et al., 2010; Wennberg et al., 2012; Peischl et al., 2013; Guha et al., 2015; Wong et al., 2015). Therefore, improved flux estimations at local scales are needed to resolve discrepancies between bottom-up and top-down approaches and improve apportionment in $\mathrm{CH}_{4}$ sources.

Inventories of $\mathrm{CH}_{4}$ fluxes suggest that emissions from US agriculture increased by more than $10 \%$ between 1990 and 2013 (EPA, 2015), and by more than $20 \%$ since between 2000 and 2015 in California (CARB, 2015). In addition, these emissions are projected to increase globally in the future due to increased food production (Tilman and Clark, 2014). Livestock in California have been estimated to account for $63 \%$ of the total agricultural emissions of greenhouse gases (mainly $\mathrm{CH}_{4}$ and $\mathrm{N}_{2} \mathrm{O}$ ); dairy cows represented more than $70 \%$ of the total $\mathrm{CH}_{4}$ emissions from the agricultural sectors in 2013 (CARB, 2015). State-wide actions are now underway to reduce $\mathrm{CH}_{4}$ emissions from dairies (ARB, 2015). Measurements at the local scale with high spatial and temporal resolution are needed to assess $\mathrm{CH}_{4}$ fluxes associated with dairy cows and to evaluate the effectiveness of changing practices to mitigate $\mathrm{CH}_{4}$ emissions from agriculture.

Space-based measurements provide the dense and continuous data sets needed to constrain $\mathrm{CH}_{4}$ emissions through inverse modeling (Streets et al., 2013). Recent studies have used the Greenhouse gases Observing SATellite (GOSAT - footprint of $\sim 10 \mathrm{~km}$ diameter) observations to quantify mesoscale natural and anthropogenic $\mathrm{CH}_{4}$ fluxes in Eurasia (Berchet et al., 2015) and in the USA (Turner et al., 2015). However, it is challenging to estimate $\mathrm{CH}_{4}$ fluxes at smaller spatial scales using satellite measurements due to their large observational footprint (Bréon and Ciais, 2010). Nevertheless, recent studies used the SCanning Imaging Absorption spectroMeter for Atmospheric CHartographY (SCIAMACHY - footprint of $60 \mathrm{~km} \times 30 \mathrm{~km}$ ) to assess emissions of a large $\mathrm{CH}_{4}$ source in the USA (Leifer et al., 2013; Kort et al., 2014).
Small-scale $\mathrm{CH}_{4}$ fluxes are often derived from in situ measurements taken at the surface and from towers (Zhao et al., 2009), and/or in situ and remote-sensing measurements aboard aircraft (Karion et al., 2013; Peischl et al., 2013; Lavoie et al., 2015; Gordon et al., 2015). A recent study emphasized the relatively large uncertainties of flux estimates from aircraft measurements using the mass balance approach in an urban area (Cambaliza et al., 2014).

Ground-based solar absorption spectrometers are powerful tools that can be used to assess local emissions (McKain et al., 2012). This technique has been used to quantify emissions from regional to urban scales (Wunch et al., 2009; Stremme et al., 2013; Kort et al., 2014; Lindenmaier et al., 2014; Hase et al., 2015; Franco et al., 2015; Wong et al., 2015; Chen et al., 2016; Kille et al., 2017).

In this study, we use four mobile ground-based total column spectrometers (called EM27/SUN, Gisi et al., 2012) to estimate $\mathrm{CH}_{4}$ fluxes from the largest dairy-farming area in the South Coast Air Basin (SoCAB), located in the city of Chino, in San Bernardino County, California. The Chino area was once home to one of the largest concentrations of dairy farms in the United States (USA), however rapid land-use change in this area may have caused $\mathrm{CH}_{4}$ fluxes from the dairy farms change rapidly in both space and time. Chen et al. (2016) used differential column measurements (downwind minus upwind column gradient $\Delta X_{\mathrm{CH}_{4}}$ across Chino) recorded on favorable meteorological conditions (e.g., constant wind direction) to verify emissions reported in the literature. In this study, the same column measurement network is employed in conjunction with meteorological data and a high-resolution model to estimate $\mathrm{CH}_{4}$ emissions at Chino for several different days, including more varying wind conditions. The approach proposed here allows us to describe the spatial distributions of $\mathrm{CH}_{4}$ emissions within and around the feedlot at very high resolution by using an advanced atmospheric modeling system applicable to any convective meteorological conditions (Gaudet et al., 2017).

In Sect. 2 of this paper, the January 2015 field campaign at Chino is described with details on the mobile column and in situ measurements. In Sect. 3, we describe the new highresolution Weather Research and Forecasting (WRF) model with large-eddy simulations (LES) setup. In Sect. 4, results of $\mathrm{CH}_{4}$ fluxes estimates are examined. Limitations of this approach, as well as suggested future analyses are outlined in Sect. 5.

\section{Measurements in the Los Angeles Basin dairy farms}

\subsection{Location of the farms: Chino, California}

Chino $\left(34.02^{\circ} \mathrm{N},-117.69^{\circ} \mathrm{W}\right)$ is located in the eastern part SoCAB, called the Inland Empire, and has historically been a major center for dairy production. With a growing population and expanding housing demand, the agricultural indus- 

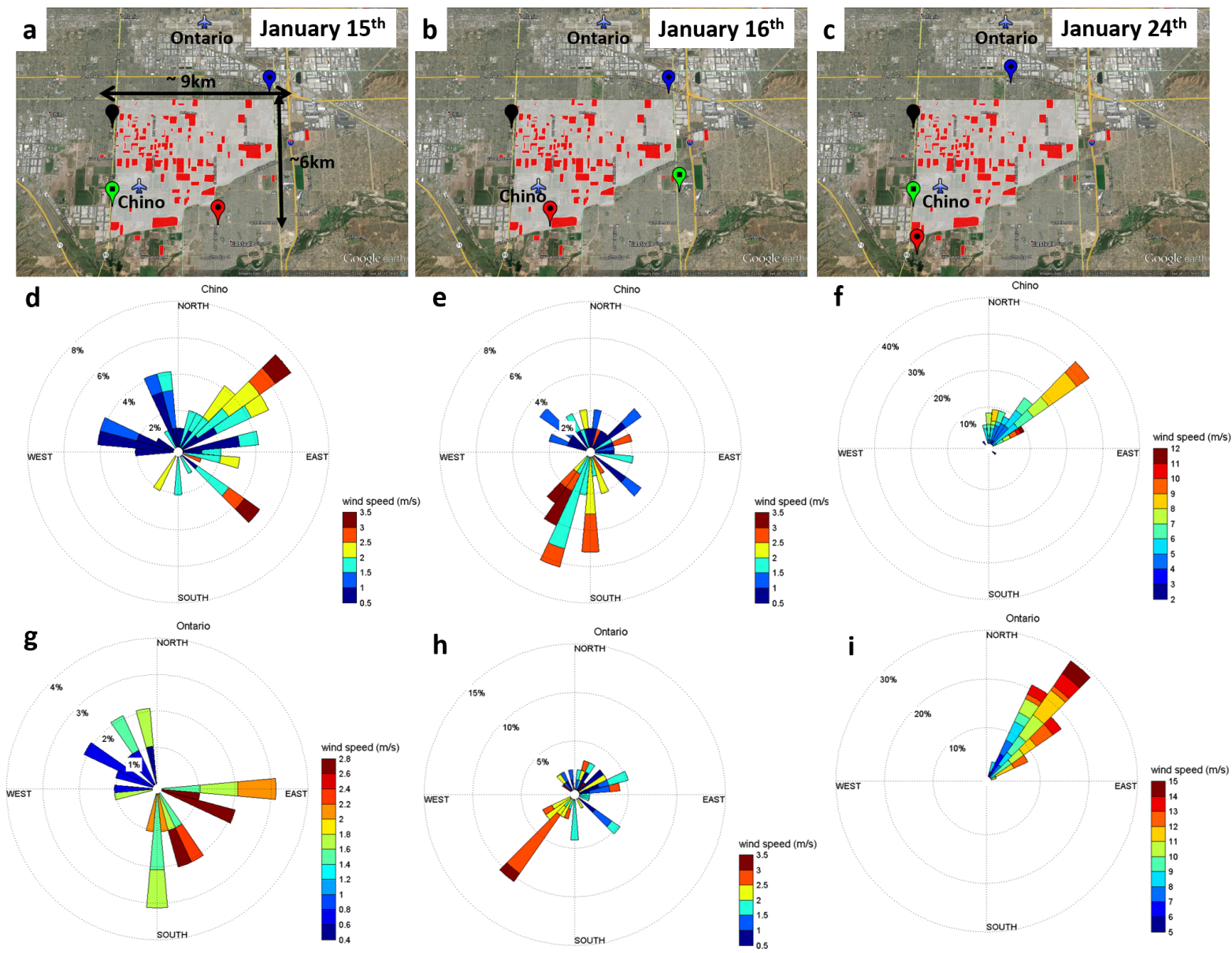

Figure 1. Three different days of measurements during the field campaign at Chino $(\sim 9 \times 6 \mathrm{~km})$ on 15 , 16, and 24 January 2015 . Panels (a-c) show the chosen locations of the four EM27/SUN (black, red, green, and blue pins correspond to the Caltech, LANL, Harvard1, and Harvard2 instruments, respectively). The red marks on the map correspond to the dairy farms. Lower panels show wind roses of 10 min averages of wind directions and wind speeds measured at the two local airports (at Chino on $\mathbf{d}-\mathbf{f}$, and at Ontario on $\mathbf{g - i}$ ). Map provided by Google Earth V 7.1.2.2041, US Dept. of State Geographer, Google, 2013, Image Landsat, Data SIO, NOAA, US, Navy, NGA, and GEBCO.

try has shrunk in this region and grown in the San Joaquin Valley (California Central Valley). The number of dairies decreased from $\sim 400$ in the 1980 s to 95 in 2013 (red area of Fig. 1a-c). Nevertheless, in $2013 \sim 90 \%$ of the southern California dairy cow population (California Agricultural Statistics, 2013) remained within the Chino area of $\sim 6 \times 9 \mathrm{~km}$ (Fig. 1). These feedlots are a major point source of $\mathrm{CH}_{4}$ in the Los Angeles Basin (Peischl et al., 2013).

\subsection{Mobile column measurements: EM27/SUN}

Atmospheric column-averaged dry-air mole fractions of $\mathrm{CH}_{4}$ and $\mathrm{CO}_{2}$ (denoted $X_{\mathrm{CH}_{4}}$ and $X_{\mathrm{CO}_{2}}$; Wunch at al., 2011) have been measured using four ground-based mobile Fourier transform spectrometers (FTS). The mobile instruments were developed by Bruker Optics and are all EM27/SUN models. The four FTS (two owned by Harvard University, denoted Harvard 1 and 2, one owned by Los Alamos National Labo- ratory, denoted LANL, and one owned by the California Institute of Technology, denoted Caltech) were initially gathered at the California Institute of Technology in Pasadena, California in order to compare them against the existing Total Carbon Column Observing Network (TCCON, Wunch et al., 2011) station and to each other, over several full days of observation. The instruments were then deployed to Chino to develop a methodology to estimate greenhouses gas emissions and improve the uncertainties on flux estimates from this major local source. Descriptions of the capacities and limitations of the mobile EM27/SUN instruments have been published in Chen et al. (2016) and Hedelius et al. (2016). Using Allan analysis, it has been found out that the precision of the differential column measurements ranges between 0.1 and $0.2 \mathrm{ppb}$ with a $10 \mathrm{~min}$ averaging time (Chen et al., 2016). For this analysis, we need to ensure that all the data from the EM27/SUN instruments are on the same scale. Here, we reference all instruments to the Harvard2 instrument. Stan- 
dardized approaches (retrieval consistency, calibrations between the instruments) are needed to monitor small atmospheric gradients using total column measurements from the EM27/SUN. Indeed we ensured all retrievals used the same algorithm, calibrated pressure sensors, and scaled retrievals according to observed, small systematic differences to reduce instrumental biases (Hedelius et al., 2016).

These modest-resolution $\left(0.5 \mathrm{~cm}^{-1}\right)$ spectrometers are equipped with solar trackers (Gisi et al., 2011) and measure throughout the day. To retrieve atmospheric total column abundances of $\mathrm{CH}_{4}, \mathrm{CO}_{2}$, and oxygen $\left(\mathrm{O}_{2}\right)$ from these nearinfrared (NIR) solar absorption spectra, we used the GGG software suite, version GGG2014 (Wunch et al., 2015). Column measurements at Chino were obtained on 5 days: 15 , 16, 22 and 24 January, and the 13 August 2015. Of these days, 15, 16, and 24 January are sufficiently cloud-free for analysis. These days have different meteorological conditions (i.e., various air temperatures, pressures, wind speeds and directions), improving the representativeness of the flux estimates at Chino.

Figure 1 shows measurements made on 15, 16, and 24 January. Wind speeds and directions, shown in the bottom panels of Fig. 1, are measured at the two local airports inside the domain (the Chino airport indicated on Fig. 1d-f and the Ontario airport Fig. 1g-i). Wind measurements from these two airports, located at less than $10 \mathrm{~km}$ apart, are made at an altitude of $10 \mathrm{~m}$ above the surface. The exact locations of the four EM27/SUN spectrometers (colored symbols in Fig. 1a-c) were chosen each morning of the field campaign to optimize the chance of measuring upwind and downwind of the plume. On 15 and 16 January, the wind speed was low with a maximum of $3 \mathrm{~ms}^{-1}$ and in a highly variable direction all day (Fig. 1d, e, and g, h); therefore the four EM27/SUN spectrometers were placed at each corner of the source area to ensure that the plume was detected by at least one of the instruments throughout the day. On the contrary, the wind on 24 January was in a constant direction from the northeast and was a relatively strong $8-10 \mathrm{~ms}^{-1}$ (Fig. If and i), so the instruments were located such that one spectrometer (Harvard2) was always upwind (blue symbols in Fig. 1) and the others are downwind of the plume and at different distances from the sources (black, green, and red symbols in Fig. 1).

\subsection{In situ measurements: Picarro}

The EM27/SUN column measurements are supplemented by ground-based in situ measurement using a commercial Picarro instruments during the January campaign. The Picarro instruments use a cavity ring-down spectroscopy (CRDS) technique that employs a wavelength monitor and attenuation to characterize species abundance.

In situ ${ }^{12} \mathrm{CH}_{4}, \mathrm{CO}_{2}$, and ${ }^{13} \mathrm{CH}_{4}$ measurements were performed on 15, 16, and 22 January, and $13 \mathrm{Au}-$ gust 2015 at roughly $2 \mathrm{~m}$ away from the LANL EM27/SUN (Fig. 1a-c) with a Picarro G2132-I instrument (Arata et al., 2016, http://www.picarro.com/products_solutions/ isotope_analyzers/). This Picarro, owned by LANL, utilize a $1 / 4^{\prime \prime}$ synflex inlet tube placed approximately $3 \mathrm{~m}$ a.g.l. (above ground level) to sample air using a small vacuum pump. Precisions on ${ }^{12} \mathrm{CH}_{4}, \mathrm{CO}_{2}$, and ${ }^{13} \mathrm{CH}_{4}$ measurements are $6 \mathrm{ppb}, 2 \mathrm{ppm}$, and $0.6 \%$, respectively.

To locate the major $\mathrm{CH}_{4}$ sources in the dairy farms area, a second Picarro G2401 instrument (http://www.picarro. com/products_solutions/trace_gas_analyzers/) from the Jet Propulsion Laboratory (JPL, Hopkins et al., 2016) was deployed on 15 January 2015. Precision on $\mathrm{CH}_{4}$ measurements is $\sim 1 \mathrm{ppb}$.

\section{Model simulations}

\subsection{Description of WRF-LES model}

The Weather Research and Forecasting (WRF) model (Skamarock et al., 2008) is an atmospheric dynamics model used for both operational weather forecasting and scientific research throughout the global community. Two key modules that supplement the baseline WRF system are used here. First, the chemistry module WRF-Chem (Grell et al., 2005) adds the capability of simulating atmospheric chemistry among various suites of gaseous and aerosol species. In this study, $\mathrm{CH}_{4}$ is modeled as a passive tracer because of its long lifetime relative to the advection time at local scales. The longest travel time from the emission source region to the instrument locations is less than $1 \mathrm{~h}$, which is extremely short compared to the lifetime of $\mathrm{CH}_{4}$ in the troposphere ( $\sim 9$ years). Therefore, no specific chemistry module is required. The version of WRF-Chem used here (Lauvaux et al., 2012) allowed for the offline coupling between the surface emissions, prescribed prior to the simulation, and their associated atmospheric tracers. Second, we make use of the large-eddy simulation (LES) version of WRF (Moeng et al., 2007) on a high-resolution model grid with $111 \mathrm{~m}$ horizontal grid spacing. A key feature of the simulation is the explicit representation of the largest turbulent eddies of the planetary boundary layer (PBL) in a realistic manner. The more typical configuration of WRF (and other atmospheric models) is to be run at a somewhat coarser resolution that is incapable of resolving PBL eddies. An advantage in this study is that the effect of the most important PBL eddies to vertical turbulent transport (i.e., the largest eddies) are not parameterized. By having a configuration with the combination of $\mathrm{CH}_{4}$ tracers and PBL eddies, we can realistically predict the evolution of released material at scales of the order of the PBL depth or smaller. The WRF-LES mode has been evaluated over Indianapolis, IN and compared to the commonly used mesoscale mode of WRF (Gaudet et al., 2017). The representation of plume structures in the horizontal and in the vertical is significantly improved at short distances $(<8 \mathrm{~km})$ compared to mesoscale simulations at $1 \mathrm{~km}$ resolution, while the meteoro- 


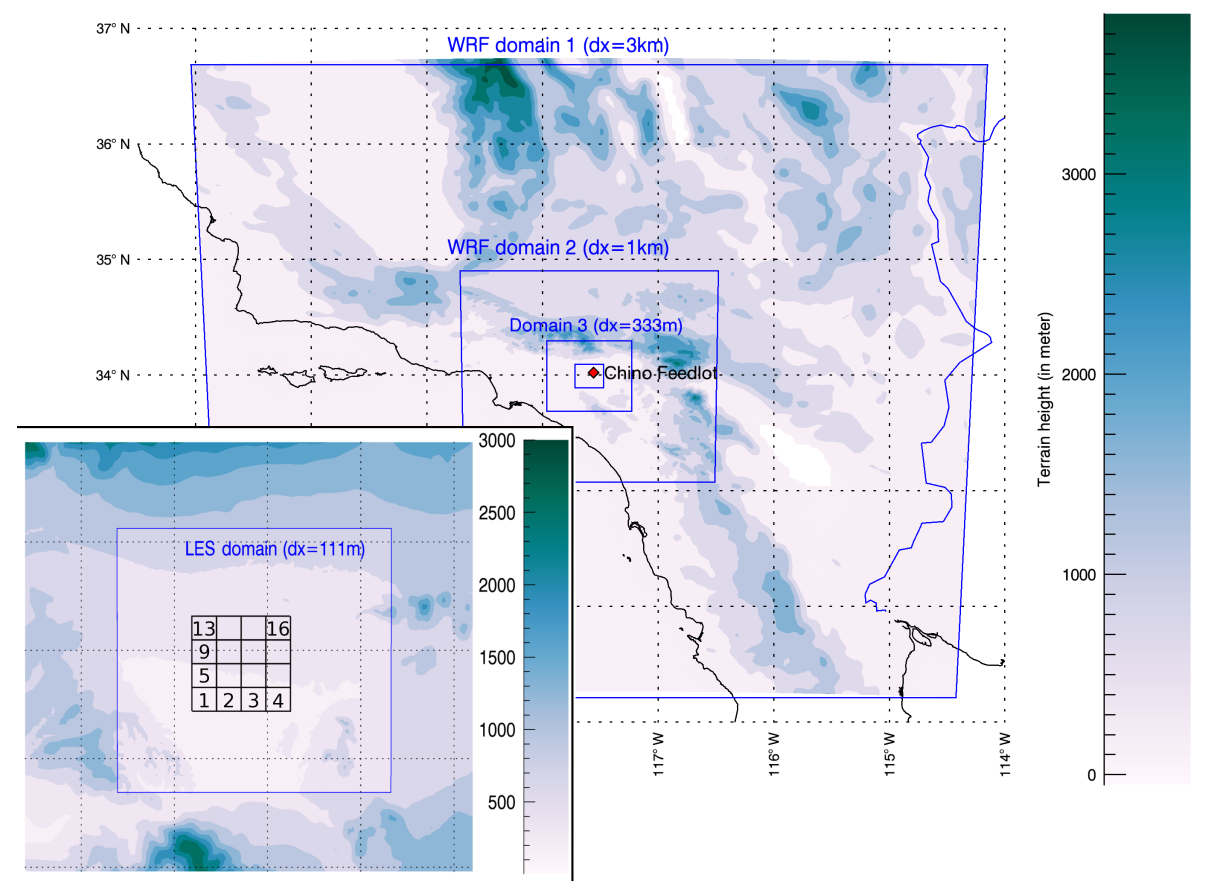

Figure 2. WRF-Chem simulation domains for the four grid resolutions ( $3 \mathrm{~km} ; 1 \mathrm{~km} ; 333 \mathrm{~m} ; 111 \mathrm{~m})$, with the corresponding topography based on the Shuttle Radar Topographic Mission digital elevation model at $90 \mathrm{~m}$ resolution). The 16 rectangular areas $\left(2 \times 2 \mathrm{~km}^{2}\right)$ are shown on the LES domain map and numerate by pixel numbers (Fig. 10).

logical performance of WRF-LES remains similar to coarser domains due to the importance of boundary nudging in the nested-domain configuration. Thus, the representation of the $\mathrm{CH}_{4}$ plumes in this study should be significantly improved with the LES mode configuration by Gaudet et al. (2017).

In this real case experiment, the model configuration consists of a series of four one-way nested grids, shown in Fig. 2 and described further in Supplement S1. Each domain contains $201 \times 201$ mass points in the horizontal, with 59 levels from the surface to $50 \mathrm{hPa}$, and the horizontal grid spacings are $3 \mathrm{~km}, 1 \mathrm{~km}, 333 \mathrm{~m}$, and $111 \mathrm{~m}$. All four domains use the WRF-Chem configuration. The model $3 \mathrm{~km}, 1 \mathrm{~km}$, and $333 \mathrm{~m}$ grids are run in the conventional mesoscale configuration with a PBL parameterization, whereas the $111 \mathrm{~m}$ grid physics is LES. The initial conditions for the cases are derived from the National Centers for Environmental Prediction (NCEP) $0.25^{\circ}$ Global Forecast System (GFS) analysis fields (i.e., $0 \mathrm{~h}$ forecast) at $6 \mathrm{~h}$ intervals. The simulations are performed from 12:00 to 00:00 UTC (04:00 to 16:00 LT) only, which corresponds to daylight hours when solar heating of the surface is present and measurements are made.

Data assimilation to optimize meteorological fields is performed using four-dimensional data assimilation (FDDA; Deng et al., 2009) for the $3 \mathrm{~km}$ and $1 \mathrm{~km}$ domains. The assimilation improves the model performance significantly (Rogers et al., 2013; Deng et al., 2017) without interfering with mass conservation and the continuity of the airflow. Surface wind and temperature measurements, including from the
Ontario (KONT) and Chino (KCNO) airport stations, and upper-air measurements were assimilated within the coarser grids using the WRF-FDDA system. However, no observations of any kind were assimilated within the 333 and $111 \mathrm{~m}$ domains; therefore, the influence of observations can only come into these two domains through the boundary between the $333 \mathrm{~m}$ and $1 \mathrm{~km}$ grids. Wind measurements at fine scale begin to resolve the turbulent perturbations, which would require additional prefiltering. These measurements are used to evaluate the WRF model performances at high resolutions.

Based on the terrain elevation in the LES domain (Fig. 2), target emissions are located in a triangular-shaped valley with the elevation decreasing gradually towards the south. However, hills nearly surround the valley along the southern perimeter. Meanwhile, the foothills of the San Gabriel Mountains begin just off the $111 \mathrm{~m}$ domain boundary to the north. As a result, the wind fields in the valley are strongly modified by local topography and can be quite different near the surface than at higher levels.

\subsection{Atmospheric inversion methodology: Bayesian framework and simulated annealing error assessment}

\subsubsection{Prior emissions errors: simulated annealing}

The definition of the prior error covariance matrix $\mathbf{B}$ is most problematic because little is known about the dairy farm 
emissions except the presence of cows distributed in lots of small areas. However, we assume no error correlation as it is known that groups of cows are distributed randomly across our inversion domain. For the definition of the variances in $\mathbf{B}$ (i.e., diagonal terms), no reliable error estimate is available because nonagricultural emissions are suspected. The lack of error estimate directly impacts the inverse emissions, and therefore results in the generation of unreliable posterior error estimates. Instead, we develop a Monte Carlo approach using a simulated annealing (SA) technique which will define the range of flux estimates for each grid point according to the observed $\mathrm{XCH} 4$ mole fractions. We test the initial errors in the emissions by creating random draws (i.e., random walk perturbing the emissions iteratively) with an error of about $200 \%$ compared to the expected emissions (based on the dairy cows' emissions from CARB, 2015). We then generated populations of random solutions and iterated 2000 times with the SA algorithm. Overall, the SA approach allows us to explore the entire space of solutions without any prior constraint. However, we assume here that each pixel is independent, possibly causing biased estimates of $\mathrm{CH}_{4}$ emissions. To avoid this problem, we only used the range of emission values for each pixel to construct our prior emission errors but discarded the total emissions from the SA. Instead, we performed a Bayesian inversion to produce total emissions for the area using the diagnosed emissions from the SA as our prior emission errors.

\subsubsection{Bayesian optimization using WRF-LES}

Due to the absence of an adjoint model in LES mode, the inverse problem is approached with Green's functions, which correspond to the convolution of the Chino dairies emissions and the WRF-LES model response. For the two independent simulations (15 and 16 January), 16 rectangular areas of $2 \times 2 \mathrm{~km}^{2}$ (Fig. 2) are defined across the feedlots to represent the state vector $(\boldsymbol{x})$ and therefore the spatial resolution of the inverse emissions, which correspond to the entire dairy farm area of about $8 \times 8 \mathrm{~km}^{2}$ once combined together. The 16 emitting areas continuously release a known number of $\mathrm{CH}_{4}$ molecules (prior estimate) during the entirety of the simulations, along with 16 individual tracers representing the 16 areas of the dairies. The final relationship between each emitting grid cell and each individual measurement location is the solution to the differential equation representing the sensitivity of each column measurement to the different $2 \times 2 \mathrm{~km}^{2}$ areas. The WRF-LES results are sampled every $10 \mathrm{~min}$ at each sampling location to match the exact measurement times and locations of the EM27/SUN instruments.

The inversion of the emissions over Chino is performed using a Bayesian analytical framework, described by the following equation:

$x=x_{0}+\mathbf{B} H^{T}\left(H \mathbf{B} H^{T}+\mathbf{R}\right)^{-1}\left(\boldsymbol{y}-H x_{0}\right)$, with $x$ the inverse emissions, $x_{0}$ the prior emissions, B the prior emission error covariance, $\mathbf{R}$ the observation error covariance, $H$ the Green's functions, and $\boldsymbol{y}$ the observed column dry-air mole fractions. The dimension of the state vector is 16 , and we assume constant $\mathrm{CH}_{4}$ emissions for each individual day. The column observations (here the vector $\boldsymbol{y}$ ) correspond to the local enhancements (i.e., the contributions of local sources), the background conditions having been subtracted beforehand. Here, we defined the background as the daily minimum for both days, measured by multiple sensors depending on the wind direction and the relative position of the sensor. Figure 3 shows that $\mathrm{CH}_{4}$ background values vary between 1.830 and $1.832 \mathrm{ppm}$, with a minimal value of $1.825 \mathrm{ppm}$ on 16 January. We used two distinct daily minimums as our final $\mathrm{CH}_{4}$ background mixing ratios. The lack of $\mathrm{CH}_{4}$ inventory for the Los Angeles Basin and the impact of transport errors on simulated $\mathrm{CH}_{4}$ mixing ratios are likely to produce larger uncertainties on the background conditions. For these reasons, upwind observations were used to define the background, assuming that spatial gradients across our simulation domain are small compared to atmospheric signals from Chino. The $\mathrm{CH}_{4}$ observations used here, after subtracting the background value, correspond to local signals of about $10 \mathrm{ppb}$ (with a peak at $25 \mathrm{ppb}$ ) compared to an uncertainty of about $2 \mathrm{ppb}$ on the background values. Two maps of 16 emission estimates are produced corresponding to the $2 \times 2 \mathrm{~km}^{2}$ areas for the 2 days (15 and 16 January). A combined inversion provides a third estimate of the emissions using $10 \mathrm{~min}$ average column data from both days. The metric used to select the best solutions is the mean absolute error (or absolute differences) between the simulated and observed column fractions. We store the solutions exhibiting a final mismatch of less than $0.01 \mathrm{ppm}$ to minimize the mismatch between observed and simulated column fractions. The optimal solution and the range of accepted emission scenarios are shown in Fig. S2. The space of solutions provide a range of accepted emissions for each $2 \times 2 \mathrm{~km}^{2}$ area that can be used as a confidence interval in the inversion results. The posterior emissions from the Bayesian inversion are then compared to the confidence interval from the SA to evaluate our final inverse emissions estimates and the posterior uncertainties. The results are presented in Sect. 4.3.

Transport errors in the WRF-LES simulation can impact the accuracy of the inversion and need to be addressed in the optimization. Deng et al. (2017) studied the sensitivity of inverse emissions due to different transport scenarios. To quantify the impact of transport errors on the inverse fluxes, an ensemble approach would be necessary to propagate transport errors in the inverse solution (e.g., Evensen, 1994). Ensemble-based techniques remain computationally expensive, especially for LES simulations. Instead, we aimed to reduce the transport errors using the WRF-FDDA system to limit the errors in wind direction, wind speed, and PBL height. The improvement in model performance is significant, as demonstrated in Deng et al. (2017), reducing 

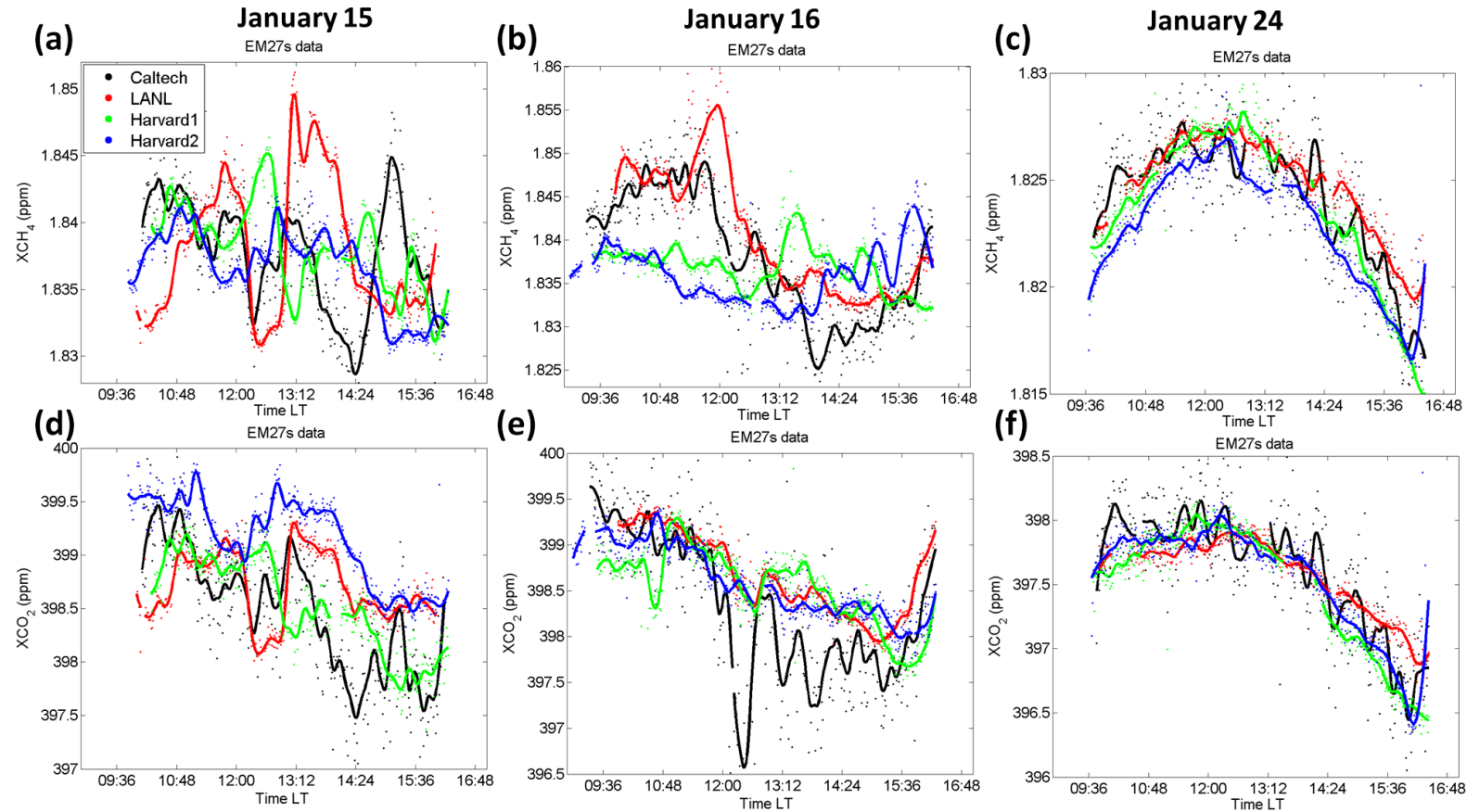

Figure 3. One minute average time series of $X_{\mathrm{CH}_{4}}$ (a-c) and $X_{\mathrm{CO}_{2}}$ (d-f) measured by the four EM27/SUN (black, red, green, and blue marks correspond to the Caltech, LANL, Harvard1, and Harvard2 spectrometers, respectively).

the wind speed and wind direction random errors by half, while removing biases in the three variables. Remaining uncertainties are described in the observation error covariance matrix $\mathbf{R}$ by balancing the normalized Chi-squared distance (Lauvaux and Davis, 2014) varying between 0.5 and $3 \mathrm{ppb}$ for all the 10 min column measurements.

\section{Results}

\subsection{Observations of $X_{\mathrm{CH}_{4}}$ and $X_{\mathrm{CO}_{2}}$ in the dairy farms}

Figure 3 shows the $1 \mathrm{~min}$ average time series of $X_{\mathrm{CH}_{4}}$ (Fig. 3a-c) and $X_{\mathrm{CO}_{2}}$ (Fig. 3d-f) derived from the four EM27/SUN. For days with slow wind $\left(\sim 3 \mathrm{~m} \mathrm{~s}^{-1}\right)$, i.e., on 15 and 16 January (Fig. 1d, e, and g, h), the maximum gradients observed between the instruments are 17 and $22 \mathrm{ppb}$ (parts per billion), and 2 and $3 \mathrm{ppm}$ (parts per million), for $X_{\mathrm{CH}_{4}}$ and $X_{\mathrm{CO}_{2}}$, respectively. Assuming that the observed Xgas changes are confined to the PBL, gradients in this layer are about 10 times larger. Gradients observed on 15 and 16 January are higher than those of $X_{\mathrm{CH}_{4}}$ and $X_{\mathrm{CO}_{2}}$ of $2 \mathrm{ppb}$ and $0.7 \mathrm{ppm}$ observed on a windy day, the $24 \mathrm{Jan}-$ uary. The $X_{\mathrm{CH}_{4}}$ and $X_{\mathrm{CO}_{2}}$ variabilities captured by the instruments are due to changes in wind speed and direction, i.e., with high $X_{\mathrm{CH}_{4}}$ signals when the wind blows from the dairies to the instruments. Thus, the EM27/SUN are clearly able to detect variability of greenhouses gases at local scales (temporal is less than $5 \mathrm{~min}$, and spatial is less than $10 \mathrm{~km}$ ) indicating that these mobile column measurements have the potential to provide estimates of local source emissions.

\subsection{Estimation of fluxes with EM27/SUN column measurements}

Total column measurements are directly linked to total emissions (McKain et al., 2012) and are sensitive to surface fluxes (Keppel-Aleks et al., 2012). To derive the total emissions of trace gases released in the atmosphere from a source region, the "mass balance" approach is often used. In its simplest form, the $X_{\mathrm{CH}_{4}}$ fluxes can be written as in Eq. (2), but this requires making assumptions on the homogeneity of the sources and wind shear in the PBL.

$F_{X_{\mathrm{CH}_{4}}}=\Delta_{X_{\mathrm{CH}_{4}}} \frac{V(z)}{m(\theta)} \mathrm{SC}_{\mathrm{air}}(z)$,

where $F_{X_{\mathrm{CH}_{4}}}$ is the flux (molecules s${ }^{-1} \mathrm{~m}^{-2}$ ), $\Delta_{X_{\mathrm{CH}_{4}}}$ is the $X_{\mathrm{CH}_{4}}$ enhancement between the upwind and the downwind region (ppb), $V$ is the average wind speed $\left(\mathrm{ms}^{-1}\right)$ from both airports, $\mathrm{m}$ is the distance in meters that air crosses over the dairies calculated as a function of the wind direction $\theta$, and $\mathrm{SC}_{\text {air }}(z)$ is the vertical column density of air $\left(\right.$ molecules $\mathrm{m}^{-2}$ ). The distances that air masses cross over the dairies $(\mathrm{m})$ before reaching a receptor (EM27/SUN) are computed for each day, each wind direction, and each instrument (see complementary information Sect. S3). 
Equation (2) can be reformulated as

$\Delta_{X_{\mathrm{CH}_{4}}}=\Delta_{t} \frac{F_{X_{\mathrm{CH}_{4}}}}{\mathrm{SC}_{\mathrm{air}}(z)}$,

where $\Delta t=\frac{m(\theta)}{V(z)}$ is the residence time of air over the dairies (in seconds).

A modified version of this mass balance approach has been used by Chen et al. (2016) to verify that the $X_{\mathrm{CH}_{4}}$ gradients measured by the EM27/SUN are comparable to the expected values measured at Chino during the CalNex aircraft campaign (Peischl et al., 2013). In Chen et al. (2016), $X_{\mathrm{CH}_{4}}$ enhancements measured between upwind and two of the downwind sites on 24 January (day of constant wind direction; Fig. 1f and i) are compared to the expected value derived from Peischl's emission numbers, which were determined using the bottom-up method and aircraft measurements. They found that the measured $X_{\mathrm{CH}_{4}}$ gradient of $\sim 2 \mathrm{ppb}$, agrees within the low range of the 2010 value. However, this differential approach, using upwind and downwind measurements, reduces the flux estimates to only 1 day (24 January), since the wind speed and direction were not constant during the other days of field measurements.

In this study, we extend the analysis of the Chino data set using the mass balance approach on steady-wind day (on 24 January) for all the FTS instruments (i.e., three downwind sites), as well as employing the other two days of measurements (15 and 16 January) in conjunction the WRF-LES model to derive a flux of $X_{\mathrm{CH}_{4}}$ from the dairy farms. We exclude measurements from 22 January and 13 August because of the presence of cirrus clouds during those days, which greatly reduce the precision of the column measurements. Our $X_{\mathrm{CH}_{4}}$ signal measured by the FTS can be decomposed as the sum of the background concentration and the enhancements due to the local sources:

$X_{\mathrm{CH}_{4} \text {, measured }}=X_{\mathrm{CH}_{4} \text {, background }}+\Delta_{X_{\mathrm{CH}_{4}}}$.

Gradients of $X_{\mathrm{CH}_{4}}\left(\Delta_{X_{\mathrm{CH}_{4}}}\right)$ are calculated relative to one instrument for the 3 days. The $X_{\mathrm{CH}_{4}}$ means (and standard deviations) over the 3 days of measurements at Chino are $1.824( \pm 0.003), 1.833( \pm 0.007), 1.823( \pm 0.003)$, and $1.835( \pm 0.010) \mathrm{ppm}$ for the Caltech, Harvard1, Harvard2, and LANL instruments, respectively. The Harvard $2 X_{\mathrm{CH}_{4}}$ mean and standard deviation are the lowest of all the observations; therefore these measurements are used as background measurements. This background site is consistent with wind directions for almost all observations, except for small periods of time on 16 January, which highlights the limitation of our method. Gradients of $X_{\mathrm{CH}_{4}}\left(\Delta_{X_{\mathrm{CH}_{4}}}\right)$ for an instrument $i$ (i.e., Caltech, Harvard1, or LANL) are the differences between each 10 min average $X_{\mathrm{CH}_{4}}$ measured by $i$ and the simultaneous 10 min average $X_{\mathrm{CH}_{4}}$ measured by the Harvard2 instrument. Details on the residence time calculation can be found in Sect. S3. Time series of anomalies for individual measurement days are presented in Fig. 4.
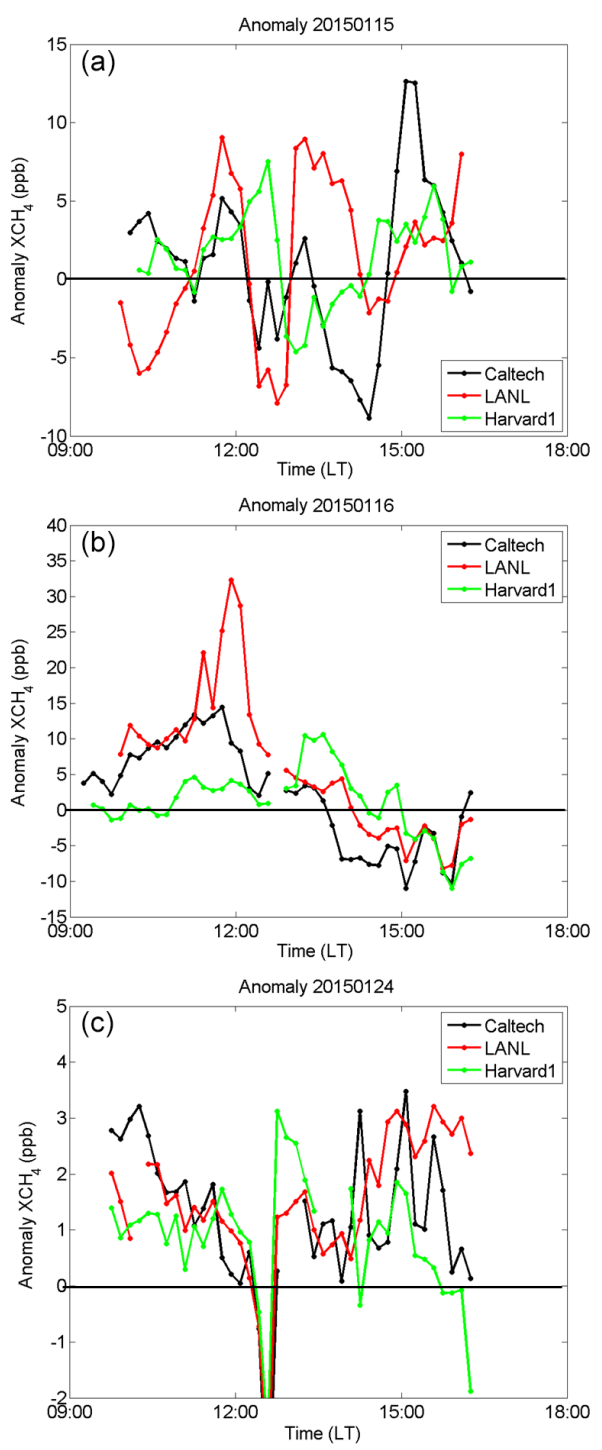

Figure 4. Time series of the 10 min-average $X_{\mathrm{CH}_{4}}$ anomaly $\left(\Delta_{X_{\mathrm{CH}_{4}}}\right.$, in $\left.\mathrm{ppb}\right)$ computed relative to the Harvard2 instrument for 15 January (a), 16 January (b), and on 24 January 2015 (c).

Assuming the background levels $X_{\mathrm{CH}_{4}}$ are similar at all the instrument sites within $10 \mathrm{~km}$ distance and steady state wind fields, Eq. (3) can be written as

$\left(X_{\mathrm{CH}_{4}, i}-X_{\mathrm{CH}_{4}, \text { Harvard2 }}\right) \propto\left(t_{i}-t_{\text {Harvard2 }}\right) \cdot F_{X_{\mathrm{CH}_{4}}}$.

A graphical representation of Eq. (5) is shown in Fig. 5 in which $\Delta_{X_{\mathrm{CH}_{4}}}$, the measured gradients by the four FTS during 24 January, are plotted as a function of $\Delta_{t}$, so that the slope corresponds to a flux in $\mathrm{ppb} \mathrm{s}^{-1}$ or ppt $\mathrm{s}^{-1}$ (parts per trillion). In this figure the slope of the blue lines (dark and light ones) represents the flux measured at Chino in previous studies (Peischl et al., 2013). These studies estimating $\mathrm{CH}_{4}$ fluxes at Chino in 2010 reported a bottom-up value of $28 \mathrm{Gg} \mathrm{yr}^{-1}$ with a range of top-down measurements from 24 to $74 \mathrm{Gg} \mathrm{yr}^{-1}$ 
Table 1. Emissions of $\mathrm{CH}_{4}$ at Chino.

\begin{tabular}{lclrr}
\hline Study & $\begin{array}{c}\text { Time } \\
\text { of } \\
\text { study }\end{array}$ & Sources & $\begin{array}{r}\mathrm{CH}_{4} \\
\text { emission } \\
\left(\mathrm{Gg} \mathrm{yr}^{-1}\right)\end{array}$ & $\begin{array}{r}\mathrm{CH}_{4} \\
\text { emission } \\
\left(\mathrm{ppt} \mathrm{s}^{-1}\right)\end{array}$ \\
\hline Peischl et al. (2013) & 2010 & inventory (dry manure + cows) & 28 & 2.5 \\
Peischl et al. (2013) & 2010 & aircraft measurements & $24-74$ & $2.1-6.5$ \\
Wennberg et al. (2012) & 2010 & inventory (wet manure + cows $)^{1}$ & 66 & 5.8 \\
CARB (2015) & 2015 & inventory (dry manure + cows) & 19 & 1.7 \\
Chen et al. (2016) & 2015 & FTS measurements only & $19-32$ & $2.4-3.3^{2}$ \\
This study & 2015 & FTS measurements only & $16-55$ & $1.4-4.8$ \\
This study & 2015 & WRF inversions & $25-39$ & $2.2-3.5$ \\
\hline
\end{tabular}

${ }^{1}$ Value reported for the SoCAB, apportioned for Chino in this study. ${ }^{2}$ Chen et al. (2016) values are used.

(Table 1). To compare these values (in $\mathrm{Gg} \mathrm{yr}^{-1}$ ) to the fluxes derived from column average (in ppt $\mathrm{s}^{-1}$ ), we used Eq. (6):

$F_{\mathrm{col}}=\frac{F \times 10^{9}}{a \cdot Y \cdot \mathrm{SC}_{a i r}(z) \cdot \frac{m_{g}}{\mathrm{Na}}} 10^{12}$,

where $F_{\text {col }}$ is the column average flux in ppts $s^{-1}, F$ the flux in $\mathrm{Gg} \mathrm{yr}^{-1}, a$ the area of Chino $\left(\mathrm{m}^{2}\right), Y$ the number of seconds in a year, $\mathrm{SC}_{\mathrm{air}}(z)$ the vertical column density of air (molecules $\left.\mathrm{m}^{-2}\right), m_{g}$ the molar mass of $\mathrm{CH}_{4}\left(\mathrm{~g} \mathrm{~mol}^{-1}\right)$, and $\mathrm{Na}$ the Avogadro constant $\left(\mathrm{mol}^{-1}\right)$.

On 24 January, when the wind speed is higher than on the other days (Fig. 1f and i), the residence time over the dairies $\left(\Delta_{t}\right)$ is reduced by a factor of 30 . The mean $\Delta_{t}$ from the closest to the furthest instruments to the upwind site are 4 min for Caltech (black square, Fig. 5), 13 min for Harvard2 (green square, Fig. 5), and $16 \mathrm{~min}$ for LANL (red square, Fig. 5). The $X_{\mathrm{CH}_{4}}$ fluxes estimated using the mean states (mass balance approach) are $4.8,1.6$, and $1.4 \mathrm{ppts}^{-1}$ for the Caltech, LANL, and Harvard 2 downwind instruments. For that day, the high wind speed causes a reduction of the methane plume width across the feedlot, which may increase uncertainties on the mass-balance approach since the FTS measurements may only detect a small portion of the total plume. Overall, the FTS network infers $X_{\mathrm{CH}_{4}}$ emissions at Chino, which are at the low end of previous top-down estimates reported by Peischl et al. (2013), consistent with the decrease in cows and farms in the Chino area over the past several years.

However, the flux estimated using the closest instrument/shortest residence time (i.e., Caltech) exceeds the value from previous studies by almost a factor of 2 . The other values from LANL and Harvard2, on the other hand, are lower than previous published values. This analysis demonstrates that, even with the day of steady-state winds and the simple geometry, the mass balance still has weaknesses, since it does not properly explain the differences seen at the three downwind sites. The close-in site exhibits the highest apparent emission rate possibly due to the proximity of a large $\mathrm{CH}_{4}$ source. This exhibits delusive approximations implied

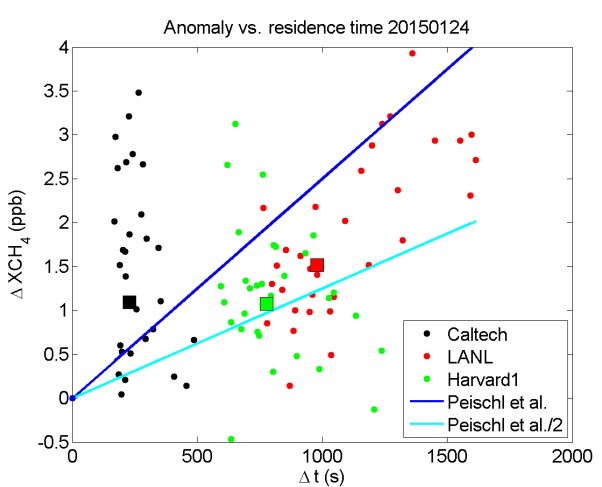

Figure 5. Estimated fluxes using FTS observations on 24 January. The 10 min anomalies (relative to the Harvard 2 instrument) are plotted against the time that air mass took to travel over the dairies, so that the slopes are equivalent to $X_{\mathrm{CH}_{4}}$ fluxes (in $\mathrm{ppbs}^{-1}$, Eq. 5). The blue (and cyan) line represents the fluxes (and half of the value) estimated at Chino in 2010 (Peischl et al., 2013). The squares are the medians of the data which correspond to the estimated fluxes using the FTS observations (in black, red and green for the Caltech, LANL, and Harvard2 instruments).

by this method (i.e., spatial inhomogeneity of $X_{\mathrm{CH}_{4}}$ sources completely averaged out and conservative transport in the domain) even on the "golden day" of strong steady-state wind pattern. Therefore, when investigating emissions at local scales these assumptions can be dubious and lead to errors in the flux estimates.

\subsection{Spatial study of the $\mathrm{CH}_{4}$ fluxes using WRF-LES data}

Analysis of the spatial sources at Chino is developed in this section using the WRF-LES model and in Sect. 4.4 with in situ Picarro measurements.

To map the sources of $\mathrm{CH}_{4}$ at Chino with the model, we focus on the 2 days of measurements during which the wind changed direction regularly (i.e., 15 and 16 January; 

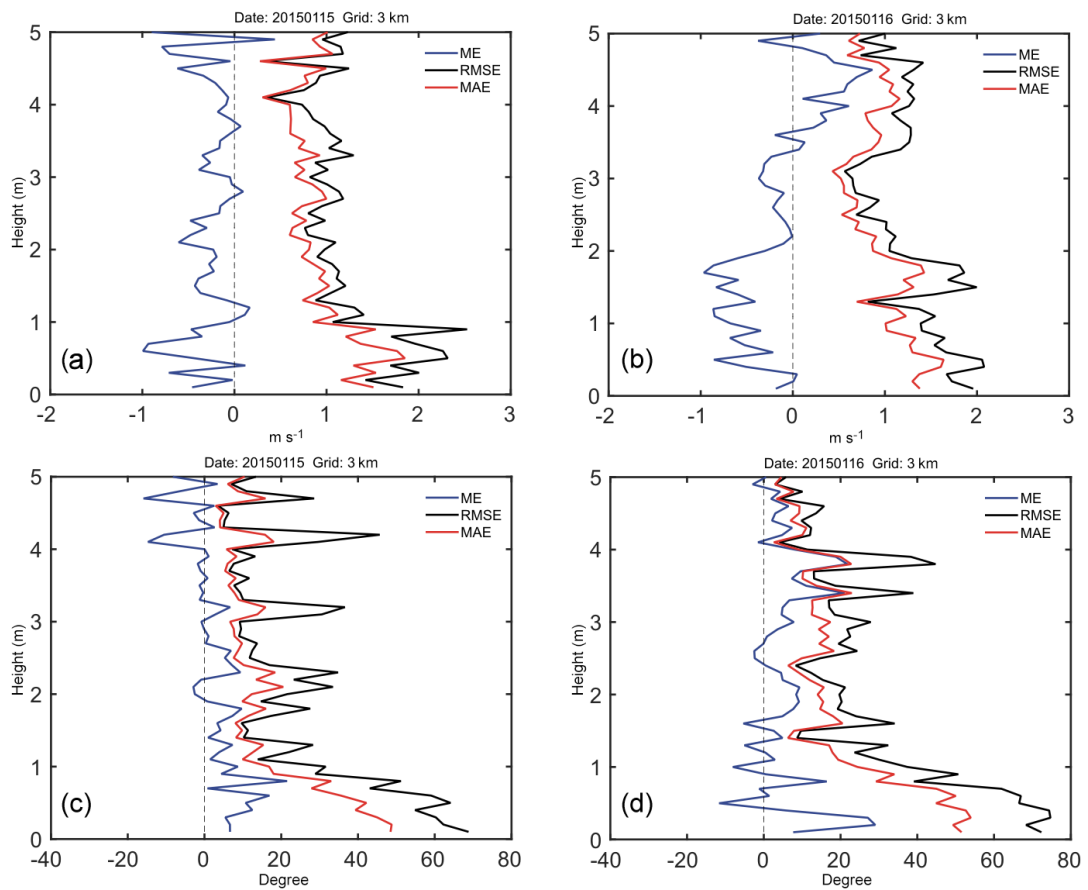

Figure 6. Vertical profiles of mean horizontal wind velocity errors (a, b) and direction (c, d) averaged from the WMO radiosonde sites available across the $3 \mathrm{~km}$ domain, with the mean absolute error (in red), the root mean square error (in black), and the mean error (in blue). Only measurements from 00:00 UTC radiosondes were used in the evaluation.

Fig. 1d, e, and g, h). This provides the model with information on the spatial distribution of $\mathrm{CH}_{4}$ emissions.

\subsubsection{WRF-LES model evaluation}

The two WRF-Chem simulations were evaluated for both days (15 and 16 January) using meteorological observations (Figs. 6 and 7). EM27 XCH4 measurements from 24 January correspond to a constant wind direction and therefore are less suitable for mapping $\mathrm{CH}_{4}$ emissions. The triangulation of sources requires changes in wind direction when using a static network of sensors. Starting with the larger region on the $3 \mathrm{~km}$ grid where WMO sondes are available (Fig. 6), model verification for both days indicates that wind speed errors averaged over the domain are about $1 \mathrm{~ms}^{-1}$ in the free atmosphere and slightly larger in the PBL (less than $2 \mathrm{~ms}^{-1}$ ). For wind direction, the mean absolute error (MAE) is less than $20^{\circ}$ in the free atmosphere and increases towards the surface, reaching a maximum of about $50^{\circ}$ there. In the PBL, where local enhancements are located, the mean error (ME) remains small, oscillating between 0 and $10^{\circ}$. At higher resolutions, the comparison between observed and WRF-predicted surface wind speed (Fig. 7) indicates that WRF is able to reproduce the overall calm wind conditions for both days at both WMO stations, Chino (KCNO) and Ontario (KONT). However, measurements below $1.5 \mathrm{~ms}^{-1}$ are not reported following the WMO standards, which limit the ability to evaluate the model over time. On 15 January at
$\mathrm{KCNO}$, consistent with the observations, all domains except the $3 \mathrm{~km}$ grid predict no surface wind speeds above $2 \mathrm{~ms}^{-1}$ from 16:00 to 19:00 UTC, except for one time from the $111 \mathrm{~m}$ LES domain. After this period, the 111 m LES domain successfully reproduces the afternoon peak in wind speed of about $3 \mathrm{~ms}^{-1}$, only slightly smaller than the observed values (3.6 ms $\mathrm{m}^{-1}$ at Chino and $3.9 \mathrm{~ms}^{-1}$ at Ontario airports). However, we should not expect perfect correspondence between the observations and the instantaneous LES output unless a low-pass filter is applied to the LES to average out the turbulence. On 16 January 2015, the model wind speed at KONT remained low throughout the day, in good agreement with the (unreported) measurements and also with available observations.

\subsubsection{Dispersion of tracers in LES mode: 15 and 16 January 2015}

We use the 15 January 2015 case as an example showing the detail in the local winds that can be provided by the highresolution LES domain. Prior to approximately 19:00 UTC (11:00 LT) a brisk easterly flow is present in the valley up to a height of $2 \mathrm{~km}$; however, near the surface, a cold pool up to several hundred meters thick developed with only a very weak easterly motion. A simulated tracer released from a location near the east edge of the Chino area stays confined to the cold pool for this period (Fig. 8, upper row panels). Solar heating causes the cold pool to break down quite rapidly af- 

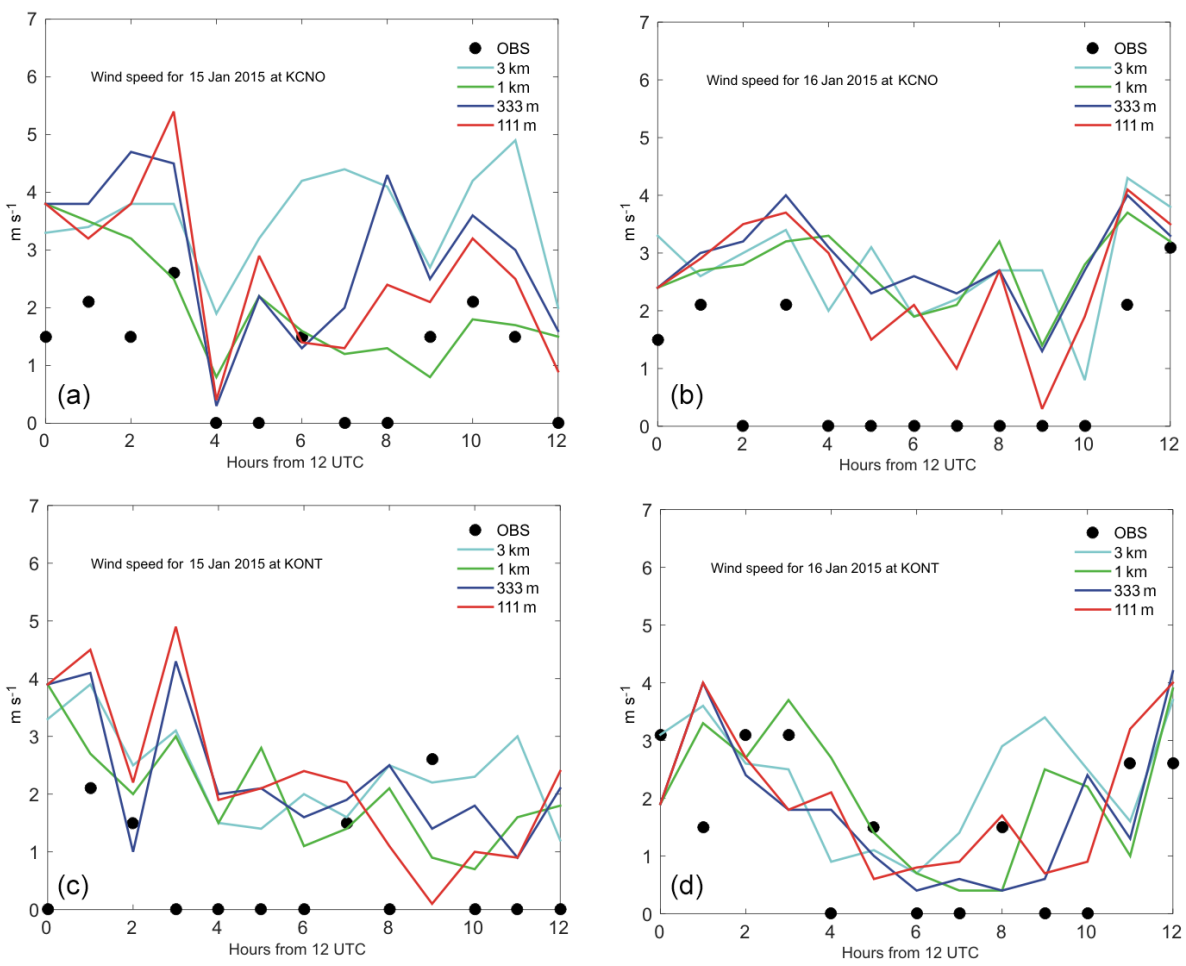

Figure 7. Mean horizontal $10 \mathrm{~m}$ wind velocity in $\mathrm{ms}^{-1}$ measured at Chino (KCNO) and Ontario (KONT) airports for 15 and 16 January (black circles) compared to the simulated wind speed for different resolutions using WRF hourly averaged results. When black circles indicate zero, the wind velocity measurements are below the WMO minimum threshold (i.e., $1.5 \mathrm{~m} \mathrm{~s}^{-1}$ ).

ter 19:00 UTC, causing the low-level wind speed to become more uniform with height (around $3 \mathrm{~ms}^{-1}$ from the east) and allowing the tracer to mix up to a height of about $1 \mathrm{~km}$ (Fig. 8, middle row panels). Beginning around 22:00 UTC (14:00 LT), however, a pulse of easterly flow scours out the valley from the east, while a surge of cooler westerly flow approaches at low levels from the west, undercutting the easterly flow. By 00:00 UTC (16:00 LT) the tracer seems to be concentrated in the cooler air just beneath the boundary of the two opposing airstreams (Fig. 8, lower row panels).

The tracer released (right column panels in Fig. 8) from an emitting $2 \times 2 \mathrm{~km}^{2}$ pixel shows complex vertical structures and two different regimes over the day. At 18:00 UTC, the tracer is concentrated near the surface, except toward the west with a maximum at $600 \mathrm{~m}$ high. At 21:00 UTC, the tracer is well-mixed in the vertical across the entire PBL, from 0 to about $\sim 1 \mathrm{~km}$, corresponding to convective conditions of daytime. At 00:00 UTC, the stability increased again, generating a low vertical plume extent with complex structures and large vertical gradients along the transect. Several updrafts and downdrafts are visible at 18:00 and 00:00 UTC, indicated by the shift in wind vectors and the distribution of the tracer in the vertical (Fig. 8). These spatial structures are unique to the LES simulation, as the PBL scheme of the mesoscale model does not reproduce turbulent eddies within the PBL.
In the horizontal, convective rolls and large tracer gradients are present, with visible fine-scale spatial structures driven by the topography (i.e., hills in the south of the domain) and turbulent eddies. Figure 9 (left panel) illustrates the spatial distribution of the mean horizontal wind at the surface over the $111 \mathrm{~m}$ simulation domain at 18:00 UTC, just prior to the scouring out of the cold pool near a large Chino feedlot. It can be seen that the near-surface air that fills the triangular valley in the greater Chino area is nearly stagnant, while much stronger winds appear on the ridges to the south. There are some banded structures showing increased wind speed near KONT to the north of the main pool of stagnant air. Figure 9 (right panel) illustrates the wind pattern for the 18:00 UTC 16 January case. The same general patterns can be seen, with the main apparent differences being reduced wind speed along the southern high ridges, and more stagnant air in the vicinity of KONT along with elevated wind speed bands near KCNO. These results emphasize how variable the wind field structures can be from point to point in the valley.

\subsubsection{Bayesian inversion and error assessment}

We present the inverse emissions from the Bayesian analytical framework with probability distribution functions from the SA in Fig. 10. The Bayesian analytical solution was com- 

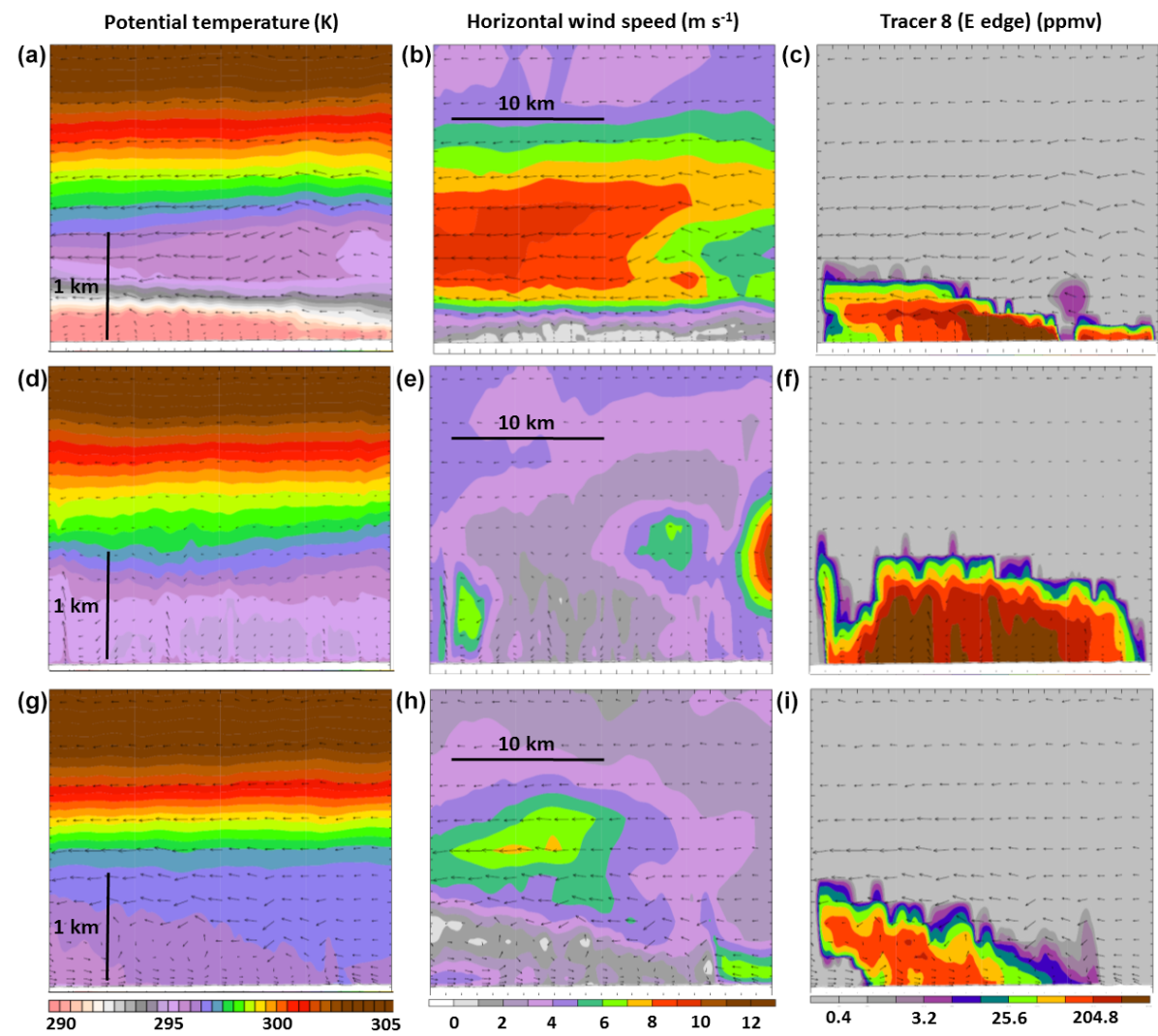

Figure 8. Vertical transects across the $111 \mathrm{~m}$ west-east WRF-LES simulation domain (pixels 5, 6, 7, and 8) at 18:00 UTC of 15 January (a-c), 21:00 UTC (d-f), and 00:00 UTC (g-i). From left to right, simulated data are shown for potential temperature (in K, a, d, g), mean horizontal wind speed and direction (in $\mathrm{ms}^{-1}$ and degree, $(\mathbf{b}, \mathbf{e}, \mathbf{h})$, and passive tracer concentration released from an eastern pixel of the emitting area (pixel 5, c, f, i), to illustrate the relationship between the three variables.
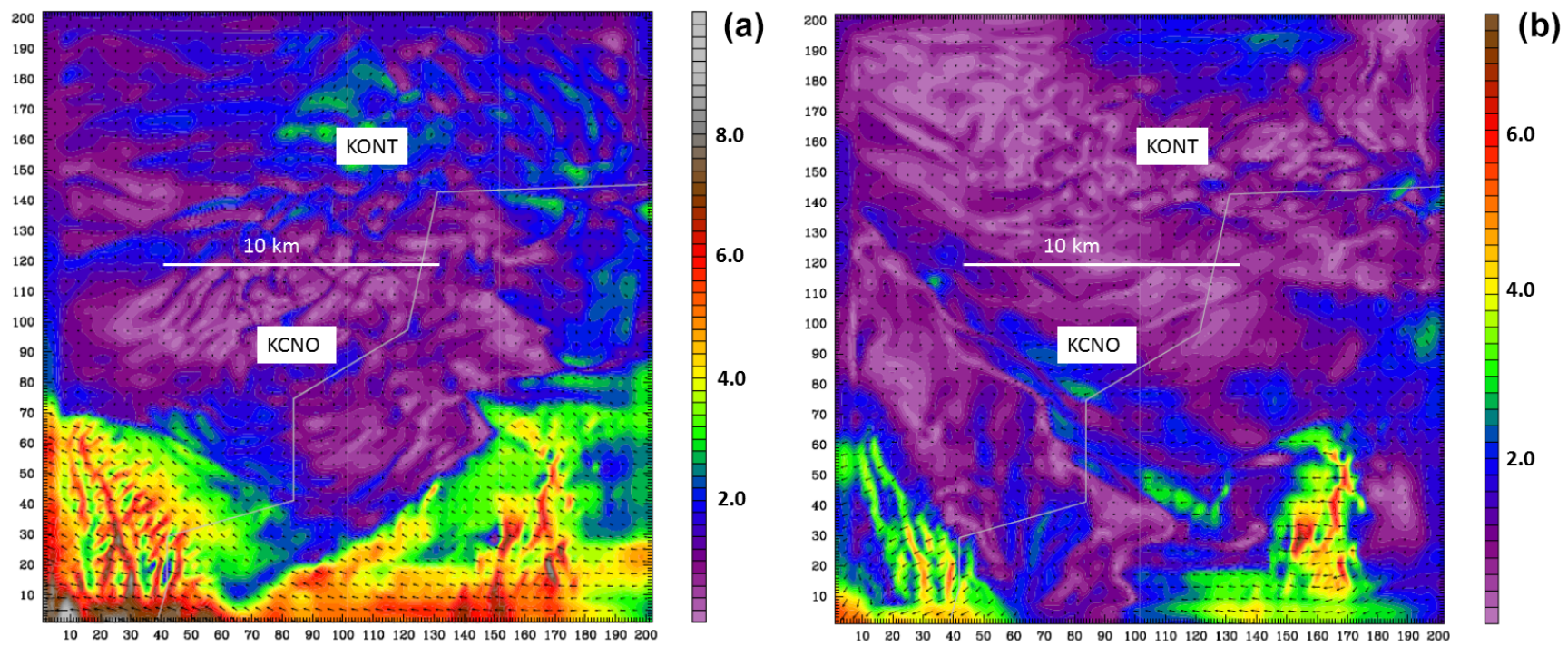

Figure 9. Mean horizontal wind field (in $\mathrm{ms}^{-1}$ ) in the first level of the domain at $111 \mathrm{~m}$ resolution simulated by WRF-LES for 15 January (a), and 16 January 2015 (b) at 18:00 UTC. High wind speeds were simulated over the hills (southern part of the domain) whereas convective rolls, corresponding to organized turbulent eddies, are visible in the middle of the domain (i.e., over the feedlots of Chino), highlighting the importance of turbulent structures in representing the observed horizontal gradients of $\mathrm{CH}_{4}$ concentrations. The locations of the Chino (KCNO) and Ontario (KONT) airports and the counties border (white line) are indicated. 

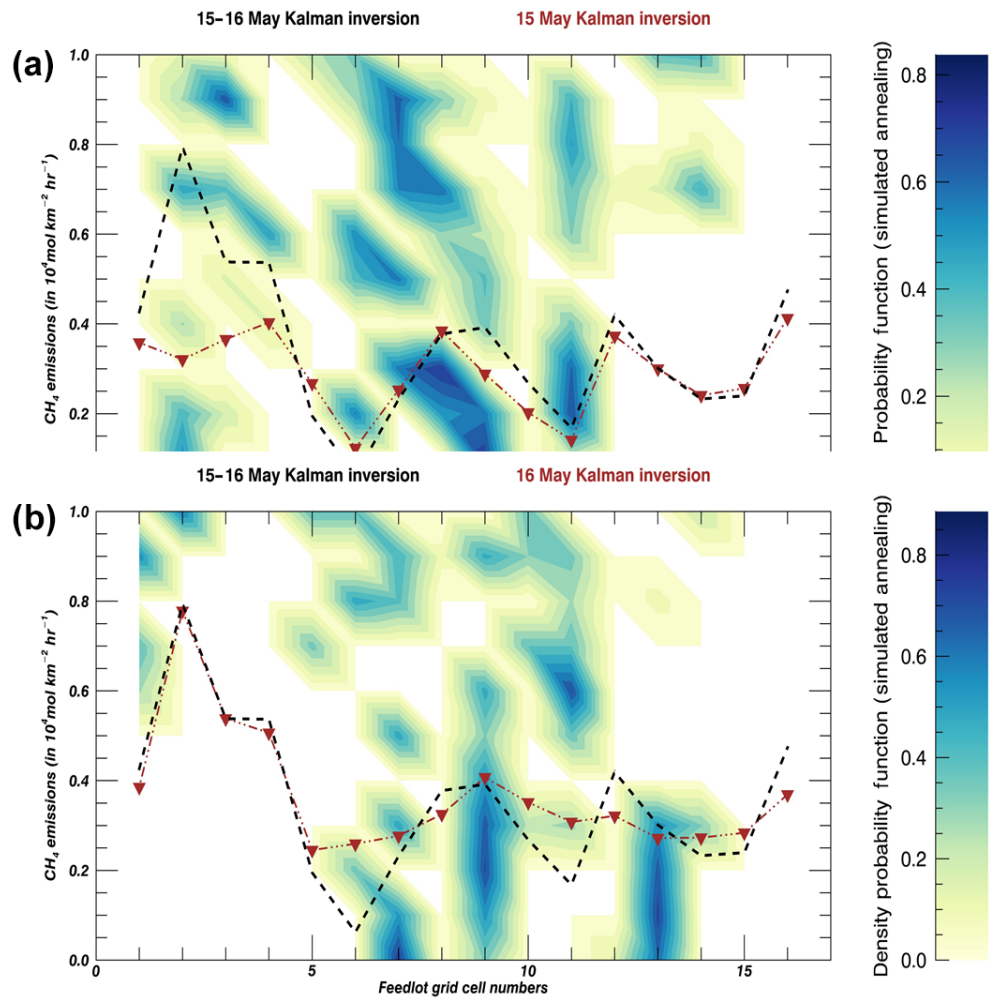

Figure 10. Emissions of $\mathrm{CH}_{4}$ (in mol km $\left.{ }^{-2} \mathrm{~h}^{-1}\right)$ for the 16 pixels $\left(2 \times 2 \mathrm{~km}^{2}\right.$ shown in Fig. 2) describing the dairies for both days, i.e., 15 January (a) and 16 January 2015 (b). The probability density function from the simulated annealing is shown in the background. The Bayesian mean emissions (see Sect. 3.2) for the 2 days combined are shown in black (dash line) and for the individual day (brown triangles).

puted for both days, assuming a flat prior emission rate of $2150 \mathrm{~mol} \mathrm{~km}^{-2} \mathrm{~h}^{-1}$ corresponding to a uniform distribution of 115000 dairy cows over $64 \mathrm{~km}^{2}$ emitting methane at a constant rate of $150 \mathrm{~kg}$ of $\mathrm{CH}_{4}$ per year (CARB, 2015), plus $18 \mathrm{~kg}$ annually per cow from dry manure management assumed to be on site (Peischl et al., 2013). The colored contours in Fig. 10 represent the probability density (or confidence level) defined by the SA analysis for the 2 days of the campaign. The Bayesian averages are moderately correlated with high confidence solutions from the SA. However, the highest value (pixel 2) coincides with high confidence for large emission values ( $>50 \%$ probability of emissions at $8000 \mathrm{~mol} \mathrm{~km}^{-2} \mathrm{~h}^{-1}$ or higher in pixels 2 or 3) which confirms that large flux signals are fairly well constrained in the inverse solution. Other pixels (i.e., 6 to 11) show a wide range of high confidence values meaning that the inverse solution is more uncertain at these locations, with few pixels being completely unconstrained (i.e., with low probabilities from the SA analysis such as pixels 15 and 16). This would possibly suggest that only the largest emissions could be attributed with sufficient confidence using these tools.

The spatial distribution of the emissions is shown in Fig. 12, which directly corresponds to the pixel emissions presented in Fig. 10. The largest sources are located in the southern part of the dairy farms area, and in the northeastern corner of the domain. Additional interpretation of these results is presented in the following section. The combination of the results from two dates (15 and 16 January) is necessary in order to identify the whole southern edge of the feedlots as a large source. Sensitivity results are presented in the discussion and in S4 and S5. The triangulation of sources performed by the inversion produced consistent results using different configurations of EM27 sensors for each day. Inversion results cover the entire domain with all wind directions being observed over the 2 days (see Fig. 1d, e and g, h). Additional sensitivity tests were performed to evaluate the impact of instrument errors, introducing a systematic error of $5 \mathrm{ppb}$ in $X_{\mathrm{CH}_{4}}$ measured by one of the EM27/SUN. The posterior emissions increased by $3-4 \mathrm{Gg} \mathrm{yr}^{-1}$ for a $+5 \mathrm{ppb}$ bias, almost independent of the location of the biased instrument. This represents $\sim 10 \%$ of the total emission at Chino.

\subsection{Spatial study of the $\mathrm{CH}_{4}$ emissions at Chino using Picarro measurements}

During the field campaign in January 2015, in situ measurements of $\mathrm{CH}_{4}, \mathrm{CO}_{2}$, as well as $\delta^{13} \mathrm{C}$ are collected simultaneously with a Picarro instrument at the same site as the LANL EM27/SUN. Fossil-related $\mathrm{CH}_{4}$ sources, such as power plants, traffic, and natural gas, emit $\mathrm{CH}_{4}$ with an iso- 
topic depletion $\delta^{13} \mathrm{C}$ ranging from -30 to $-45 \%$, whereas biogenic methane sources, such as those from enteric fermentation and wet and dry manure management in dairies and feedlots emit in the range of -65 to $-45 \%$ (TownsendSmall et al., 2012). During the January 2015 campaign, the $\delta^{13} \mathrm{C}$ at Chino ranged from -35 to $-50 \%$, indicating a mixture of fossil and biogenic sources, respectively. Most of the air sampled included a mixture of both sources. However, the measurements with the highest $\mathrm{CH}_{4}$ concentrations had the lowest ${ }^{13} \mathrm{C}$ signatures, suggesting that the major $\mathrm{CH}_{4}$ enhancements measured by the Picarro instrument can be attributed to the dairy farms and not the surrounding urban sources.

On 16 and 22 January, the Picarro and the LANL EM27/SUN were installed at the southwestern side of the largest dairies in Chino (red pin, Fig. 1b), near a wet lagoon that is used for manure management (, $150 \mathrm{~m}$ away). For these days, the Picarro measured enhancements of $\mathrm{CH}_{4}$ up to $20 \mathrm{ppm}$ above background concentrations, demonstrating that the lagoon is a large source of $\mathrm{CH}_{4}$ emissions in the Chino area. The location of the lagoon was identified and verified by satellite imagery, visual inspection, and also with measurements from the second Picarro instrument deployed in the field on 15 January 2015. With this instrument, $\mathrm{CH}_{4}$ spikes up to $23 \mathrm{ppm}$ were observed near the wet manure lagoon. The measurements from both Picarros and the LANL EM27/SUN instrument near the lagoon suggested that this is a significant local source of $\mathrm{CH}_{4}$ emissions in the Chino area.

As opposed to column measurements, Picarro measurements are very sensitive to the dilution effect of gases in the PBL. With a low boundary layer, atmospheric constituents are concentrated near the surface, and the atmospheric signal detected by the in situ surface measurements is enhanced relative to the daytime, when the PBL is fully developed. For this reason, additional Picarro measurements were made at night on 13 August 2015, when the PBL height is minimal. Between 04:00 and 07:00 LT, we performed Picarro measurements at different locations in Chino to map the different sources of $\mathrm{CH}_{4}$ and verify that the large sources observed in January, such as the lagoon, are still emitting in summer. Figure 11 shows the scatter plot of 1 min-average anomalies of $\mathrm{CH}_{4}\left(\Delta_{\mathrm{CH}_{4}}\right)$ vs. $\mathrm{CO}_{2}\left(\Delta_{\mathrm{CO}_{2}}\right)$, colored by the $\delta^{13} \mathrm{C}$ values, measured by the Picarro on the night of 13 August 2015. During that night, the isotopic range of $\delta^{13} \mathrm{C}$ in sampled methane ranged from -45 to $-65 \%$. These low $\delta^{13} \mathrm{C}$ values are consistent with the expectation that the sources of $\mathrm{CH}_{4}$ in the Chino area are dominated by biogenic emissions from dairy cows. In the feedlots (side triangles, Fig. 11), $\Delta_{\mathrm{CH}_{4}}$ and $\Delta_{\mathrm{CO}_{2}}$ are well correlated $\left(r^{2}=0.90\right)$, because cows emit both gases (Kinsman et al., 1995). The observed $\Delta_{\mathrm{CH}_{4}} / \Delta_{\mathrm{CO}_{2}}$ emission ratio, $48 \pm 1.5 \mathrm{ppb} \mathrm{ppm}^{-1}$, is in good agreement with a previous study measuring this ratio from cows' breath (Lassen et al., 2012). Measurements obtained at less than $1 \mathrm{~m}$ away from cows (circles, Fig. 11) had the lowest the $\delta^{13} \mathrm{Cob}$ served, $\sim-65 \%$, and these points scale well with the linear

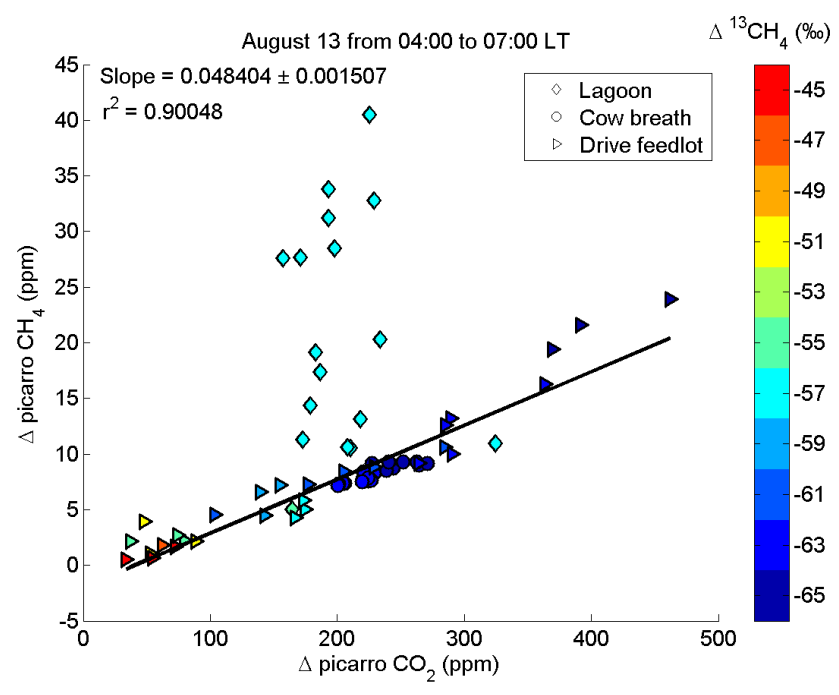

Figure 11. Scatter plot of $1 \mathrm{~min}$-average anomalies (from the $5 \mathrm{~min}$ smoothed) of $\mathrm{CH}_{4}$ vs. $\mathrm{CO}_{2}$, color coded using the delta $\mathrm{CH}_{4}$ values, measured by the Picarro on 13 August from 04:00 to 07:00 LT.

correlation observed during the survey. This confirms that the emission ratio derived by surveying the feedlots is representative of biogenic emissions related to enteric fermentation. For, measurements obtained next to the lagoon (diamond marks, Fig. 11), the ${ }^{12} \mathrm{CH}_{4}$ concentrations were enhanced by up to $40 \mathrm{ppm}$ above background levels observed that night, while the relative enhancement of $\mathrm{CO}_{2}$ was much smaller. This extremely large $\mathrm{CH}_{4}$ enhancement relative to $\mathrm{CO}_{2}$ indicates a signature of $\mathrm{CH}_{4}$ emissions from wet manure management (lagoon), confirming that there is significant heterogeneity in the $\mathrm{CH}_{4}$ sources within the Chino dairy area.

\section{Discussion}

The fluxes derived by the FTS observations and the WRFLES inversions, as well as previous reported values, are summarized in Table 1.

The top-down $\mathrm{CH}_{4}$ estimate using FTS observations in Chino provides a range of fluxes from 1.4 to $4.8 \mathrm{ppt} \mathrm{s}^{-1}$ during January 2015 (Table 1), which are on the lower end of previously published estimates. These values of $\mathrm{CH}_{4}$ flux estimates for January 2015 based on the FTS measurements are consistent with the decrease in cows in Chino over the past several years as urbanization has spread across the region. The mass balance approach uses a simple characterization of the background $X_{\mathrm{CH}_{4}}$ that can be applied to any deployment of EM27 sensors. As described in Sect. S3, emissions are estimated using the average residence time between the sensor locations based on meteorological measurements. The wind direction has not been considered here to perform a site selection and define background $X_{\mathrm{CH}_{4}}$ mole fractions. Therefore, 
the range of emissions from our analysis may be larger possibly due to variations in the observed enhancements when the mean wind direction changes frequently over the day. The approach presented here could be improved by collecting wind direction measurements co-located to EM27 sensors to help define the boundary conditions (as described in Lauvaux et al., 2016).

Considering the decrease in the number of dairy cows by $\sim 20 \%$ from 2010 to 2015 , and using the emission factor of $168 \mathrm{~kg} \mathrm{yr}^{-1}$ per head (CARB, 2015 inventory: enteric fermentation + dry manure management), the $\mathrm{CH}_{4}$ flux associated with dairy cows at Chino decreased from 2.0 to $1.7 \mathrm{ppts}^{-1}$, which agrees well with our low flux estimates derived from FTS observations. However, fluxes derived using the simple mass balance approach differ from each other, exhibiting the limitations of this method, even on a golden day (steady-state wind day on 24 January). The WRF-LES inversions (Figs. 10 and 12) and mobile in situ measurements using the Picarro instrument (Fig. 11) indicate that the $\mathrm{CH}_{4}$ sources are not homogeneous within this local area. In addition, wind measurements from the two local airports typically disagree regarding the direction and speed (Fig. 1d-i), and the WRF-LES tracer results indicate nonhomogeneous advection of tracers (Fig. 8, right panels).

Figure 12 shows the map of the a posteriori $X_{\mathrm{CH}_{4}}$ fluxes (mean of 15 and 16 January runs) from the WRF-LES simulations, superimposed on a Google Earth map, with the location of dairy farms represented by the red areas. The domain is decomposed into 16 boxes (Sect. 3.2), in which the colors correspond to the a posteriori emissions derived from the WRF-LES inversions. Red (blue) colors of a box mean more (less) $\mathrm{CH}_{4}$ emissions compared to the a priori emissions, which correspond to the dairy cow emissions contained in the CARB 2015 inventory (emission factor multiplied by the number of cows). Results of the inversion exhibit more $\mathrm{CH}_{4}$ emissions at the southern and the northeastern parts of the domain, as well as emissions corresponding to dairy cows in the center of the area.

The higher $\mathrm{CH}_{4}$ emissions from the southwestern part of the domain can be attributed to the wet manure lagoon (yellow pin, Fig. 12) in January 2015. During the night of $13 \mathrm{Au}-$ gust 2015, Picarro measurements confirmed that the lagoon was still wet and emitted a considerable amount of $\mathrm{CH}_{4}$ relative to $\mathrm{CO}_{2}$ (Fig. 12). The second mobile Picarro instrument from JPL was deployed on 15 January 2015 and measured $\mathrm{CH}_{4}$ spikes up to $23 \mathrm{ppm}$ near the wet manure lagoon. The WRF-LES model also suggests higher methane fluxes in these regions (red boxes, Fig. 12). The CARB 2015 inventory estimates that manure management practices under wet (e.g., lagoon) conditions emit more $\mathrm{CH}_{4}$ than the dairy cows themselves: $187 \mathrm{~kg} \mathrm{CH}_{4} \mathrm{cow}^{-1} \mathrm{yr}^{-1}$ from wet manure management, $18 \mathrm{~kg} \mathrm{CH}_{4} \mathrm{cow}^{-1} \mathrm{yr}^{-1}$ from dry management practices, and $150 \mathrm{~kg} \mathrm{CH}_{4} \mathrm{cow}^{-1} \mathrm{yr}^{-1}$ from enteric fermentation in the stomachs of dairy cows. Therefore, we expect that measurements in which the lagoon emissions were de-

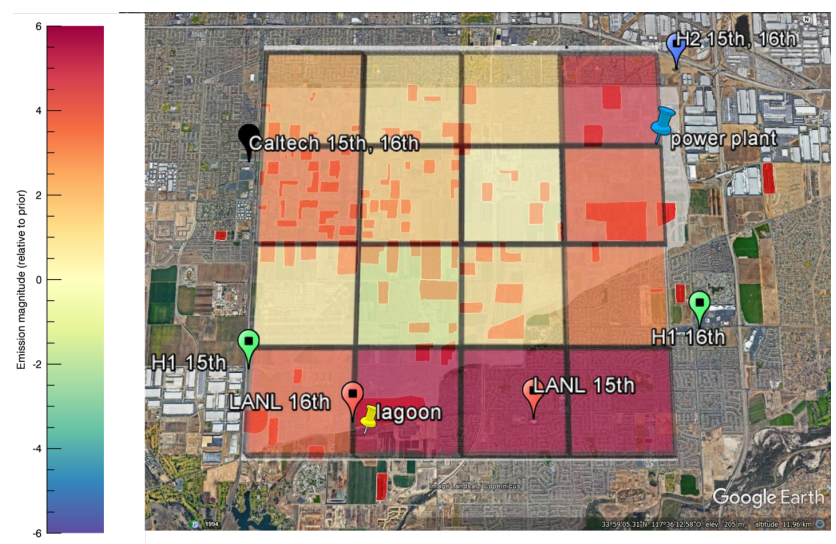

Figure 12. Map of the a posteriori $X_{\mathrm{CH}_{4}}$ fluxes (mean of 15 and 16 January runs) from the WRF-LES simulations normalized by the a priori emissions and superimposed on a Google Earth map, where the dairy farms are represented by the red areas as shown in Fig. 1. The domain is decomposed in 16 boxes $(2 \mathrm{~km} \times 2 \mathrm{~km})$, in which the colors correspond to the a posteriori emissions from the WRF-LES inversions. Red (blue) colors mean more (less) $\mathrm{CH}_{4}$ emissions than dairy cows in that box. A multiplicative ratio of 1 is equivalent to a flux of $2150 \mathrm{~mol} \mathrm{~km}^{-2} \mathrm{~h}^{-1}$. The locations of the lagoon (yellow pin) and the power plant (blue pin) are also added to the map. Map provided by Google Earth V 7.1.2.2041, US Dept. of State Geographer, Google, 2013, Image Landsat, Data SIO, NOAA, US, Navy, NGA, and GEBCO.

tected by our instruments will lead to higher methane fluxes in the local region compared to measurements that detect emissions from enteric fermentation in cows alone. Bottomup emission inventory of $\mathrm{CH}_{4}$ is 2 times higher when considering wet lagoons (Wennberg et al., 2012) instead of dry management practices (Peischl et al., 2013) at Chino (Table 1). The location and extent of wet lagoons in the Chino region is not expected to be constant with time and could be altered due to changing land use and future development in the area. Bottom-up estimates of $\mathrm{CH}_{4}$ emissions from dairies in the Chino region could be further improved if the extent and location of wet manure lagoons were well known.

The WRF-LES model also suggests higher methane fluxes in the southeast (red boxes, Fig. 12). No dairy farms are located in these areas, but an interstate pipeline is located nearby; thus these $\mathrm{CH}_{4}$ enhancements could be attributed to natural gas. The ${ }^{13} \mathrm{CH}_{4}$ Picarro measurements indicate that the Chino area is influenced by both fossil- and biogenic-related methane sources. A recent study has suggested the presence of considerable fugitive emissions of methane at Chino (http://www.edf.org/climate/ methanemaps/city-snapshots/los-angeles-area), probably due to the advanced age of the pipelines. Natural gas leaks in the Chino area were not specifically targeted during the time of this field campaign and cannot be confirmed using available data. This possibility should thus be confirmed by future studies. 
In addition to possible fugitive emissions at Chino, the inversion also predicts higher $\mathrm{CH}_{4}$ flux in the northeastern region of the study domain, which is in the vicinity of a power plant that reportedly emits a $\mathrm{CH}_{4}$ flux roughly equivalent to one cow per year (only including enteric fermentation) (http://www.arb.ca.gov/cc/reporting/ghg-rep/reported_ data/ghg-reports.htm). Further analysis and measurements of fossil methane sources in the Chino area would help to verify potential contributions from fossil methane sources, including power plants and/or fugitive natural gas pipeline emissions.

Overall, FTS and in situ Picarro measurements, as well as WRF-LES inversions, all demonstrate that the $\mathrm{CH}_{4}$ sources at Chino are heterogeneous, with a mixture of emissions from enteric fermentation, wet and dry manure management practices, and possible additional fossil methane emissions (from natural gas pipeline and power plants). The detection of $\mathrm{CH}_{4}$ emissions in the Chino region and discrepancies between top-down estimates could be further improved with more FTS observations and concurrent in situ methane isotopes measurements combined with high-resolution WRFLES inversions. This would improve the spatial detection of the $\mathrm{CH}_{4}$ emissions at Chino in order to ameliorate the inventories among the individual sources in this local area.

\section{Summary and conclusions}

In January 2015, four mobile low-resolution FTS (EM27/SUN) were deployed in a $\sim 6 \times 9 \mathrm{~km}$ area in Chino (California) to assess $\mathrm{CH}_{4}$ emissions related to dairy cows in the SoCAB farms. The network of column measurements captured large spatial and temporal gradients of greenhouses gases emitted from this small-scale area. Temporal variabilities of $X_{\mathrm{CH}_{4}}$ and $X_{\mathrm{CO}_{2}}$ can reach up to $20 \mathrm{ppb}$ and $2 \mathrm{ppm}$, respectively, within less than a $10 \mathrm{~min}$ interval with respect to wind direction changes. This study demonstrates that these mobile FTS are therefore capable of detecting local greenhouses gas signals and these measurements can be used to improve the verification of $X_{\mathrm{CO}_{2}}$ and $X_{\mathrm{CH}_{4}}$ emissions at local scales.

Top-down estimates of $\mathrm{CH}_{4}$ fluxes using the 2015 FTS observations in conjunction with wind measurements are 1.4$4.8 \mathrm{ppt} \mathrm{s}^{-1}$, which are in the low end of the 2010 estimates (Peischl et al., 2013), consistent with the decrease in cows in the Chino area. During this campaign, FTS measurements were collected in close proximity to the sources (less than a few kilometers) in order to capture large signals from the local area. The main advantage of this type of deployment strategy is to better constrain the emissions while avoiding vertical mixing issues in the model with the use of column measurements in the inversion (Wunch et al., 2011). Therefore, the model transport errors, which often limit the capacity of the model flux estimates, are considerably reduced. However, the close proximity of the measurements to the sources makes the assumptions on the homogeneity of the sources and wind patterns questionable.

The FTS and the Picarro measurements detected various $\mathrm{CH}_{4}$ signatures over Chino, with extreme $\mathrm{CH}_{4}$ enhancements measured near a wet lagoon (Picarro and FTS measurements enhanced by $40 \mathrm{ppm} \mathrm{CH}_{4}$ and $60 \mathrm{ppb} X_{\mathrm{CH}_{4}}$, respectively) and possible fugitive fossil-related $\mathrm{CH}_{4}$ emissions in the area (indicated by higher $\delta^{13} \mathrm{C}$ values than expected from biogenic emissions alone).

Wind speed and direction measurements derived from the two local airports (less than $10 \mathrm{~km}$ apart), as well as the WRF meteorological simulations at different FTS sites, differ greatly, suggesting that an assumption of steady horizontal wind can be improved upon in the use of the mass balance approach in our study.

This study demonstrates the value of using mobile column measurements for the detection of local $\mathrm{CH}_{4}$ enhancements and the estimation of $\mathrm{CH}_{4}$ emissions when these measurements are combined with modeling. High-resolution (111 m) WRF-LES simulations were performed on two dates, constrained by four column measurements each day, to map the heterogeneous $\mathrm{CH}_{4}$ sources at Chino. The optimized emissions (i.e., average a posteriori flux) over the domain are $1.3 \mathrm{ppt} \mathrm{s}^{-1}$ when only considering the boxes in the center of the domain and $2.6 \mathrm{ppt} \mathrm{s}^{-1}$ when all the boxes are averaged. A major emitter (a wet manure lagoon) was identified by the inversion results, and is supported by in situ ${ }^{13} \mathrm{CH}_{4}$ measurements collected during the campaign. The $\mathrm{CH}_{4}$ flux estimates are within the range of the top-down mass balance emissions derived with the four FTS and estimates reported by Peischl et al. (2013) (i.e., 2.1 to $6.5 \mathrm{ppt} \mathrm{s}^{-1}$ ), showing that column measurements combined with high-resolution modeling can detect and be used to estimate $\mathrm{CH}_{4}$ emissions.

The instrumental synergy (mobile in situ and column observations) coupled with a comprehensive high-resolution model simulations allow the estimation of local $\mathrm{CH}_{4}$ fluxes, and can be useful for improving emission inventories, especially in a complex megacity area, where the different sources are often located within small areas.

This study highlights the complexity of estimating emissions at local scale when sources and wind can exhibit heterogeneous patterns. Long-term column observations and/or aircraft eddy covariance measurements could improve estimations.

Data availability. The atmospheric data are available upon request (camille.viatte@latmos.ipsl.fr) or as an electronic Supplement to the paper.

The Supplement related to this article is available online at https://doi.org/10.5194/acp-17-7509-2017-supplement. 
Competing interests. The authors declare that they have no conflict of interest.

Acknowledgements. The authors thank NASA and the W. M. Keck Institute for Space Studies for financial support. MKD acknowledges NASA CMS support of the EM27/SUN deployment and LANL-LDRD 20110081DR for acquisition of the instrument. Jia Chen, Taylor Jones, Jonathan E. Franklin, and Steve Wofsy gratefully acknowledge funding provided by the National Science Foundation through MRI Award 1337512. A portion of this research was carried out at the Jet Propulsion Laboratory, California Institute of Technology, under a contract with the National Aeronautics and Space Administration. The January campaign participants are Camille Viatte, Jacob Hedelius, Harrison Parker, Jia Chen, Johnathan Franklin, Taylor Jones, Riley Duren, and Kristal Verhulst.

Edited by: P. Monks

Reviewed by: two anonymous referees

\section{References}

Arata, C., Rahn, T., and Dubey, M. K.: Methane Isotope Instrument Validation and Source Identification at Four Corners, New Mexico, United States, J. Phys. Chem. A, 120, 1488-1494, https://doi.org/10.1021/acs.jpca.5b12737, 2016.

ARB - Air Resources Board: concept paper, full report, available at: http://www.arb.ca.gov/cc/shortlived/concept_paper.pdf, last access: 7 May 2015.

Berchet, A., Pison, I., Chevallier, F., Paris, J.-D., Bousquet, P., Bonne, J.-L., Arshinov, M. Y., Belan, B. D., Cressot, C., Davydov, D. K., Dlugokencky, E. J., Fofonov, A. V., Galanin, A., Lavrič, J., Machida, T., Parker, R., Sasakawa, M., Spahni, R., Stocker, B. D., and Winderlich, J.: Natural and anthropogenic methane fluxes in Eurasia: a mesoscale quantification by generalized atmospheric inversion, Biogeosciences, 12, 5393-5414, https://doi.org/10.5194/bg-12-5393-2015, 2015.

Breon, F. M. and Ciais, P.: Spaceborne remote sensing of greenhouse gas concentrations, Comptes Rendus Geoscience, 342, 412-424, https://doi.org/10.1016/j.crte.2009.09.012, 2010.

California Agricultural Statistics, United States Department of Agriculture, National Agricultural Statistics Service, Pacific Regional, Field Office California, full report, available at: http: //www.nass.usda.gov/Statisticsby_State/California/Publications/ California_Ag_Statistics/CALivestockandDairy.pdf (last access: 16 June 2017), 2013.

Cambaliza, M. O. L., Shepson, P. B., Caulton, D. R., Stirm, B., Samarov, D., Gurney, K. R., Turnbull, J., Davis, K. J., Possolo, A., Karion, A., Sweeney, C., Moser, B., Hendricks, A., Lauvaux, T., Mays, K., Whetstone, J., Huang, J., Razlivanov, I., Miles, N. L., and Richardson, S. J.: Assessment of uncertainties of an aircraft-based mass balance approach for quantifying urban greenhouse gas emissions, Atmos. Chem. Phys., 14, 9029-9050, https://doi.org/10.5194/acp-14-9029-2014, 2014.

CARB - California Air Resources Board: California Greenhouse Gas Emission Inventory, 2015 Edn., available at: http://www. arb.ca.gov/cc/inventory/data/data.htm (last access: 6 June 2017), 2015.

Chen, J., Viatte, C., Hedelius, J. K., Jones, T., Franklin, J. E., Parker, H., Gottlieb, E. W., Wennberg, P. O., Dubey, M. K., and Wofsy, S. C.: Differential Column Measurements Using Compact SolarTracking Spectrometers, Atmos. Chem. Phys., 16, 8479-8498, https://doi.org/10.5194/acp-16-8479-2016, 2016.

Ciais, P., Sabine, C., Bala, G., Bopp, L., Brovkin, V., Canadell, J., Chhabra, A., DeFries, R., Galloway, J., Heimann, M., Jones, C., Le Quéré, C., Myneni, R. B., Piao, S., and Thornton, P.: Carbon and Other Biogeochemical Cycles, in: Climate Change 2013 The Physical Science Basis. Contribution of Working Group I to the Fifth Assessment Report of the Intergovernmental Panel on Climate Change, edited by: Stocker, T. F., Qin, D., Plattner, G.K., Tignor, M., Allen, S. K., Boschung, J., Nauels, A., Xia, Y., Bex, V., and Midgley, P. M., Cambridge University Press, Cambridge, UK and New York, NY, USA, 2013.

Deng, A., Stauffer, D., Gaudet, B., Dudhia, J., Hacker, J., Bruyere, C., Wu, W., Vandenberghe, F., Liu, Y., and Bourgeois, A.: Update on WRF-ARW end-to-end multi-scale FDDA system, in: 10th Annual WRF Users' Workshop, 23 June 2009, Boulder, CO, 2009.

Deng, A., Lauvaux, T., Davis, K.J., Gaudet, B. J., Miles, N. L., Richardson, S. J., Wu, K., Sarmiento, D. P., Hardesty, R. M., Bonin, T. A., Brewer, W. A., and Gurney, K. R.: Toward reduced transport errors in a high resolution urban $\mathrm{CO}_{2}$ inversion system, Elementa, 2017, 5-20, https://doi.org/doi.org/10.1525/elementa.133, 2017.

EPA - Environmental Protection Agency: Sources of Greenhouses Gases Emissions: addresses anthropogenic emissions from agricultural activities (not including fuel combustion and sewage emissions, which are addressed in the Energy and Waste chapters), full report, available at: http://www.epa.gov/climatechange/Downloads/ghgemissions/ US-GHG-Inventory-2015-Chapter-5-Agriculture.pdf (last access: 19 January 2017), 2015.

Evensen, G.: Sequential data assimilation with a nonlinear quasi-geostrophic model using Monte Carlo methods to forecast error statistics, J. Geophys. Res., 99, 10143-10162, https://doi.org/10.1029/94JC00572, 1994.

Forster, P., Ramaswamy, V., Artaxo, P., Berntsen, T., Betts, R., Fahey, D. W., Haywood, J., Lean, J., Lowe, D. C., Myhre, G., Nganga, J., Prinn, R., Raga, G. M. S., and Van Dorland, R.: Changes in Atmospheric Constituents and in Radiative Forcing, in: Climate Change 2007: The Physical Science Basis, Contribution of Working Group I to the Fourth Assessment Report of the Intergovernmental Panel on Climate Change, edited by: Solomon, S., Quin, D., Manning, M., Chen, Z., Marquis, M., Averyt, K. B., Tignor, M., and Miller, H., Cambridge University Press, Cambridge, UK, 500-657, https://doi.org/10.1017/CBO9781107415324, 2007.

Franco, B., Hendrick, F., Van Roozendael, M., Müller, J.-F., Stavrakou, T., Marais, E. A., Bovy, B., Bader, W., Fayt, C., Hermans, C., Lejeune, B., Pinardi, G., Servais, C., and Mahieu, E.: Retrievals of formaldehyde from ground-based FTIR and MAX-DOAS observations at the Jungfraujoch station and comparisons with GEOS-Chem and IMAGES model simulations, Atmos. Meas. Tech., 8, 1733-1756, https://doi.org/10.5194/amt-81733-2015, 2015. 
Gaudet, B. J., Lauvaux, T., Deng, A., and Davis, K. J.: Exploration of the impact of nearby sources on urban atmospheric inversions using large eddy simulation, Elementa, in review, 2017.

Gisi, M., Hase, F., Dohe, S., and Blumenstock, T.: Camtracker: a new camera controlled high precision solar tracker system for FTIR-spectrometers, Atmos. Meas. Tech., 4, 47-54, https://doi.org/10.5194/amt-4-47-2011, 2011.

Gisi, M., Hase, F., Dohe, S., Blumenstock, T., Simon, A., and Keens, A.: $\mathrm{XCO}_{2}$-measurements with a tabletop FTS using solar absorption spectroscopy, Atmos. Meas. Tech., 5, 2969-2980, https://doi.org/10.5194/amt-5-2969-2012, 2012.

Gordon, M., Li, S.-M., Staebler, R., Darlington, A., Hayden, K., O'Brien, J., and Wolde, M.: Determining air pollutant emission rates based on mass balance using airborne measurement data over the Alberta oil sands operations, Atmos. Meas. Tech., 8, 3745-3765, https://doi.org/10.5194/amt-8-3745-2015, 2015.

Grell, G. A., Peckham, S. E., Schmitz, R., McKeen, S. A., Frost, G., Skamarock, W. C., and Eder, B.: Fully coupled online chemistry within the WRF model, Atmos. Environ., 39, 6957-6975, 2005.

Guha, A., Gentner, D. R., Weber, R. J., Provencal, R., and Goldstein, A. H.: Source apportionment of methane and nitrous oxide in California's San Joaquin Valley at CalNex 2010 via positive matrix factorization, Atmos. Chem. Phys., 15, 12043-12063, https://doi.org/10.5194/acp-15-12043-2015, 2015.

Hase, F., Frey, M., Blumenstock, T., Groß, J., Kiel, M., Kohlhepp, R., Mengistu Tsidu, G., Schäfer, K., Sha, M. K., and Orphal, J.: Use of portable FTIR spectrometers for detecting greenhouse gas emissions of the megacity Berlin - Part 2: Observed time series of $\mathrm{XCO}_{2}$ and $\mathrm{XCH}_{4}$, Atmos. Meas. Tech. Discuss., 8, 27672791, https://doi.org/10.5194/amtd-8-2767-2015, 2015.

Hedelius, J. K., Viatte, C., Wunch, D., Roehl, C. M., Toon, G. C., Chen, J., Jones, T., Wofsy, S. C., Franklin, J. E., Parker, H., Dubey, M. K., and Wennberg, P. O.: Assessment of errors and biases in retrievals of $X_{\mathrm{CO}_{2}}, X_{\mathrm{CH}_{4}}, X_{\mathrm{CO}}$, and $X_{\mathrm{N}_{2} \mathrm{O}}$ from a $0.5 \mathrm{~cm}^{-1}$ resolution solar-viewing spectrometer, Atmos. Meas. Tech., 9, 3527-3546, https://doi.org/10.5194/amt-9-3527-2016, 2016.

Hiller, R. V., Neininger, B., Brunner, D., Gerbig, C., Bretscher, D., Künzle, T., Buchmann, N., and Eugster, W.: Aircraft-based $\mathrm{CH}_{4}$ flux estimates for validation of emissions from an agriculturally dominated area in Switzerland, J. Geophys. Res.-Atmos., 119, 4874-4887, https://doi.org/10.1002/2013JD020918, 2014.

Histov, A. N., Johnson, K. A., and Kebreab, E.: Livestock methane emissions in the United States, P. Natl. Acad. Sci. USA, 111, E1320, https://doi.org/10.1073/pnas.1401046111, 2014.

Hopkins, F. M., Kort, E. A., Bush, S. E.,Ehleringer, J. R., Lai, C.-T., Blake, D. R., and Randerson, J. T.: Spatial patterns and source attribution of urban methane in the Los Angeles Basin, J. Geophys. Res.-Atmos., 121, 2490-2507, https://doi.org/10.1002/2015JD024429, 2016.

Hsu, Y.-K., VanCuren, T., Park, S., Jakober, C., Herner, J., FitzGibbon, M., Blake, D. R., and Parrish, D. D.: Methane emissions inventory verification in southern California, Atmos. Environ., 44, 1-7, https://doi.org/10.1016/j.atmosenv.2009.10.002, 2010.

IPCC - Intergovernmental Panel on Climate Change: Climate Change 2013: the physical science basis, in: Contribution of working group I to the fifth Assessment report of the Intergovernmental Panel On Climate Change, edited by: Stocker, T. F., Qin, D., Plattner, G.-K., Tignor, M., Allen, S. K., Boschung, J.,
Nauels, A., Xia, Y., Bex, V., and Midgley, P. M., Cambridge University Press, Cambridge, UK and New York, NY, USA, 1535 pp., 2013.

Karion, A., Sweeney, C., Pétron, G., Frost, G., Michael Hardesty, R., Kofler, J., Miller, B. R., Newberger, T., Wolter, S., Banta, R., Brewer, A., Dlugokencky, E., Lang, P., Montzka, S. A., Schnell, R., Tans, P., Trainer, M., Zamora, R., and Conley, S.: Methane emissions estimate from airborne measurements over a western United States natural gas field, Geophys. Res. Lett., 40, 43934397, https://doi.org/10.1002/grl.50811, 2013.

Keppel-Aleks, G., Wennberg, P. O., Washenfelder, R. A., Wunch, D., Schneider, T., Toon, G. C., Andres, R. J., Blavier, J.-F., Connor, B., Davis, K. J., Desai, A. R., Messerschmidt, J., Notholt, J., Roehl, C. M., Sherlock, V., Stephens, B. B., Vay, S. A., and Wofsy, S. C.: The imprint of surface fluxes and transport on variations in total column carbon dioxide, Biogeosciences, 9, 875891, https://doi.org/10.5194/bg-9-875-2012, 2012.

Kille, N., Baidar, S., Handley, P., Ortega, I., Sinreich, R., Cooper, O. R., Hase, F., Hannigan, J. W., Pfister, G., and Volkamer, R.: The CU mobile Solar Occultation Flux instrument: structure functions and emission rates of $\mathrm{NH}_{3}, \mathrm{NO}_{2}$ and $\mathrm{C}_{2} \mathrm{H}_{6}$, Atmos. Meas. Tech., 10, 373-392, https://doi.org/10.5194/amt-10-3732017, 2017.

Kinsman, R., Sauer, F. D., Jackson, H. A., and Wolynetz, M. S.: Methane and Carbon Dioxide Emissions from Dairy Cows in Full Lactation Monitored over a Six-Month Period, J. Dairy Sci., 78, 2760-2766, https://doi.org/10.3168/jds.S00220302(95)76907-7, 1995.

Kort, E. A., Frankenberg, C., Costigan, K. R., Lindenmaier, R., Dubey, M. K., and Wunch, D.: Four corners: The largest US methane anomaly viewed from space, Geophys. Res. Lett., 41, 6898-6903, https://doi.org/10.1002/2014GL061503, 2014.

Lassen, J., Lovendahl, P., and Madsen, J.: Accuracy of noninvasive breath methane measurements using Fourier transform infrared methods on individual cows, J. Dairy Sci., 95, 890-898, https://doi.org/10.3168/jds.2011-4544, 2012.

Lauvaux, T. and Davis, K. J. : Planetary boundary layer errors in mesoscale inversions of column-integrated $\mathrm{CO}_{2}$ measurements, J. Geophys. Res.-Atmos., 119, 490-508, https://doi.org/10.1002/2013JD020175, 2014.

Lauvaux, T., Schuh, A., Bocquet, M., Wu, L., Richardson, S., Miles, N., and Davis, K.: Network design for mesoscale inversions of $\mathrm{CO}_{2}$ sources and sinks, Tellus B, 64, 17980, https://doi.org/10.3402/tellusb.v64i0.17980, 2012.

Lauvaux, T., Miles, N. L., Deng, A., Richardson, S. J., Cambaliza, M. O., Davis, K. J., Gaudet, B., Gurney, K. R., Huang, J., Karion, A., Oda, T., Patasaruk, R., Razlivanov, I., Sarmiento, D., Shepson, P., Sweeney, C., Turnbull, J., and Wu, $\mathrm{K}$.: High resolution atmospheric inversion of urban $\mathrm{CO}_{2}$ emissions during the dormant season of the Indianapolis Flux Experiment (INFLUX), J. Geophys. Res.-Atmos., 121, 5213-5236, https://doi.org/10.1002/2015JD024473, 2016.

Lavoie, T. N., Shepson, P. B., Cambaliza, M. O. L., Stirm, B. H., Karion, A., Sweeney, C., Yacovitch, T. I., Herndon, S. C., Lan, X., and Lyon, D.: Aircraft-Based Measurements of Point Source Methane Emissions in the Barnett Shale Basin, Environ. Sci. Technol., 49, 7904-7913, https://doi.org/10.1021/acs.est.5b00410, 2015. 
Leifer, I., Culling, D., Schneising, O., Farrell, P., Buchwitz, M., and Burrows, J. P.: Transcontinental methane measurements: Part 2. Mobile surface investigation of fossil fuel industrial fugitive emissions, Atmos. Environ., 74, 432-441, https://doi.org/10.1016/j.atmosenv.2013.03.018, 2013.

Lindenmaier, R., Dubey, M. K., Henderson, B. G., Butterfield, Z. T., Herman, J. R., Rahn, T., and Lee, S.-H.: Multiscale observations of $\mathrm{CO}_{2},{ }^{13} \mathrm{CO}_{2}$, and pollutants at Four Corners for emission verification and attribution, P. Natl. Acad. Sci. USA, 111, 83868391, 2014.

McKain, K., Wofsy, S. C., Nehrkorn, T., Eluszkiewicz, J., Ehleringer, J. R., and Stephens, B. B.: Assessment of groundbased atmospheric observations for verification of greenhouse gas emissions from an urban region, P. Natl. Acad. Sci. USA, 109, 8423-8428, https://doi.org/10.1073/pnas.1116645109, 2012.

Miller, S. M., Wofsy, S. C., Michalak, A. M., Kort, E. A., Andrews, A. E., Biraud, S. C., Dlugokencky, E. J., Eluszkiewicz, J., Fischer, M. L., Janssens-Maenhout, G., Miller, B. R., Miller, J. B., Montzka, S. A., Nehrkorn, T., and Sweeney, C.: Anthropogenic emissions of methane in the United States, P. Natl. Acad. Sci. USA, 110, 20018-20022, https://doi.org/10.1073/pnas.1314392110, 2013.

Moeng, C.-H., Dudhia, J., Klemp, J., and Sullivan, P.: Examining two-way grid nesting for large eddy simulation of the PBL using the WRF model, Mon. Weather Rev., 135, 2295-2311, https://doi.org/10.1175/MWR3406.1, 2007.

Myhre, G., Shindell, D., Bréon, F.-M., Collins, W., Fuglestvedt, J., Huang, J., Koch, D., Lamarque, J.-F., Lee, D., Mendoza, B., Nakajima, T., Robock, A., Stephens, G., Takemura, T., and Zhang, H.: Anthropogenic and Natural Radiative Forcing, in: Climate Change 2013: The Physical Science Basis. Contribution of Working Group I to the Fifth Assessment Report of the Intergovernmental Panel on Climate Change, edited by: Stocker, T. F., Qin, D., Plattner, G.-K., Tignor, M., Allen, S. K., Boschung, J., Nauels, A., Xia, Y., Bex, V., and Midgley, P. M., Cambridge University Press, Cambridge, UK and New York, NY, USA, 2013.

Nisbet, E. and Weiss, R.: Top-down versus bottom-up, Science, 328, 1241-1243, https://doi.org/10.1126/science.1189936, 2010.

Peischl, J., Ryerson, T. B., Brioude, J., Aikin, K. C., Andrews, A. E., Atlas, E., Blake, D., Daube, B. C., de Gouw, J. A., Dlugokencky, E., Frost, G. J., Gentner, D. R., Gilman, J. B., Goldstein, A. H., Harley, R. A., Holloway, J. S., Kofler, J., Kuster, W. C., Lang, P. M., Novelli, P. C., Santoni, G. W., Trainer, M., Wofsy, S. C., and Parrish, D. D.: Quantifying sources of methane using light alkanes in the Los Angeles basin, California, J. Geophys. Res.-Atmos., 118, 4974-4990, https://doi.org/10.1002/jgrd.50413, 2013.

Rogers, R. E., Deng, A., Stauffer, D. R., Gaudet, B. J., Jia, Y., Soong, S., and Tanrikulu, S.: Application of the Weather Research and Forecasting Model for Air Quality Modeling in the San Francisco Bay Area, J. Appl. Meteorol., 52, 1953-1973, 2013.

Skamarock, W. C., Klemp, J. B., Dudhia, J., Gill, D. O., Barker, D. M., Duda, M. G., Huang, X.-Y., Wang, W., and Powers, J. G.: A description of the Advanced Research WRF version 3, NCAR Technical Note 475, http://www2.mmm.ucar.edu/wrf/ users/docs/arw_v3.pdf (last access: 16 June 2017), 2008.
Streets, D. G., Canty, T., Carmichael, G. R., de Foy, B., Dickerson, R. R., Duncan, B. N., Edwards, D. P., Haynes, J. A., Henze, D. K., Houyoux, M. R., Jacob, D. J., Krotkov, N. A., Lamsal, L. N., Liu, Y., Lu, Z., Martin, R. V., Pfister, G. G., Pinder, R. W., Salawitch, R. J., and Wecht, K. J.: Emissions estimation from satellite retrievals: a review of current capability, Atmos. Environ., 77, 1011-1042, https://doi.org/10.1016/j.atmosenv.2013.05.051, 2013.

Stremme, W., Grutter, M., Rivera, C., Bezanilla, A., Garcia, A. R., Ortega, I., George, M., Clerbaux, C., Coheur, P.-F., Hurtmans, D., Hannigan, J. W., and Coffey, M. T.: Top-down estimation of carbon monoxide emissions from the Mexico Megacity based on FTIR measurements from ground and space, Atmos. Chem. Phys., 13, 1357-1376, https://doi.org/10.5194/acp13-1357-2013, 2013

Tilman, D. and Clark, M.: Global diets link environmental sustainability and human health, Nature, 515, 518-522, https://doi.org/10.1038/nature13959, 2014.

Townsend-Small, A., Tyler, S. C., Pataki, D. E., Xu, X., and Christensen, L. E.: Isotopic measurements of atmospheric methane in Los Angeles, California, USA reveal the influence of "fugitive" fossil fuel emissions, J. Geophys. Res., 117, D07308, https://doi.org/10.1029/2011JD016826, 2012.

Turner, A. J., Jacob, D. J., Wecht, K. J., Maasakkers, J. D., Lundgren, E., Andrews, A. E., Biraud, S. C., Boesch, H., Bowman, K W., Deutscher, N. M., Dubey, M. K., Griffith, D. W. T., Hase, F., Kuze, A., Notholt, J., Ohyama, H., Parker, R., Payne, V. H., Sussmann, R., Sweeney, C., Velazco, V. A., Warneke, T., Wennberg, P. O., and Wunch, D.: Estimating global and North American methane emissions with high spatial resolution using GOSAT satellite data, Atmos. Chem. Phys., 15, 7049-7069, https://doi.org/10.5194/acp-15-7049-2015, 2015.

US Climate Action Plan: Strategy to reduce methane, full report, https://obamawhitehouse.archives.gov/sites/default/files/ strategy_to_reduce_methane_emissions_2014-03-28_final.pdf (last access: 16 June 2017), March 2014.

Wennberg, P. O., Mui, W., Wunch, D., Kort, E. A., Blake, D. R., Atlas, E. L., Santoni, G. W., Wofsy, S. C., Diskin, G. S., Joeng, S., and Fischer, M. L.: On the sources of methane to the Los Angeles atmosphere, Environ. Sci. Technol., 46, 9282-9289, https://doi.org/10.1021/es301138y, 2012.

Wong, K. W., Fu, D., Pongetti, T. J., Newman, S., Kort, E. A., Duren, R., Hsu, Y.-K., Miller, C. E., Yung, Y. L., and Sander, S. P.: Mapping $\mathrm{CH}_{4}: \mathrm{CO}_{2}$ ratios in Los Angeles with CLARSFTS from Mount Wilson, California, Atmos. Chem. Phys., 15, 241-252, https://doi.org/10.5194/acp-15-241-2015, 2015.

Wunch, D., Wennberg, P. O., Toon, G. C., Keppel-Aleks, G., and Yavin, Y. G.: Emissions of greenhouse gases from a North American megacity, Geophys. Res. Lett., 36, L15810, https://doi.org/10.1029/2009GL039825, 2009.

Wunch, D., Toon, G. C., Blavier, J.-F. L., Washenfelder, R. A., Notholt, J., Connor, B. J., Griffith, D. W. T., Sherlock, V., and Wennberg, P. O.: The total carbon column observing network, Philos. T. Roy. Soc. A, 369, 2087-2112, https://doi.org/10.1098/rsta.2010.0240, 2011. 
Wunch, D., Toon, G. C., Sherlock, V., Deutscher, N. M., Liu, C., Feist, D. G., and Wennberg, P. O.: The Total Carbon Column Observing Network's GGG2014 Data Version, 43, https://doi.org/10.14291/tccon.ggg2014.documentation.R0/1221662, 2015.
Zhao, C., Andrews, A. E., Bianco, L., Eluszkiewicz, J., Hirsch, A., MacDonald, C., Nehrkorn, T., and Fischer, M. L.: Atmospheric inverse estimates of methane emissions from Central California, J. Geophys. Res., 114, D16302, https://doi.org/10.1029/2008JD011671, 2009. 